\title{
Nuevas narrativas en televisión: La Realidad Aumentada en los telediarios de Antena 3
}

\author{
Television and new narratives: The use of Augmented Reality on Antena 3 \\ news
}

\author{
Azkunaga García, L., Gaztaka Eguskiza, I. y Eguskiza Sesumaga, L. ${ }^{1}$ \\ Recibido: 15-05-2019 - Aceptado: 10-08-2019 \\ DOI: https://doi.org/10.26441/RC18.2-2019-A2
}

\begin{abstract}
RESUMEN: La innovación tecnológica se alía con las nuevas narrativas periodísticas en un contexto de amplia oferta informativa, donde los medios buscan diferenciarse y generar una mayor interactividad hacia sus audiencias. Esta investigación analiza el uso de la Realidad Aumentada (RA) como herramienta informativa en los telediarios de Antena 3, entre enero y abril de 2019. La cadena española de televisión es pionera en implantar esta tecnología de visualización que recrea situaciones inmersivas superponiendo la realidad física a otras virtuales.

El propósito es identificar las temáticas más susceptibles a la utilización de la RA, así como su forma, interactividad y funciones. Con un claro propósito informativo, este recurso se asocia principalmente a noticias de interés general con cierta previsión o perdurabilidad en el tiempo. Además, se esbozan los principales rasgos de una innovadora escenografía envolvente que promueve un mayor acercamiento entre presentador/a y espectadores, favoreciendo la comprensión y asimilación de las informaciones.
\end{abstract}

Palabras clave: realidad aumentada; televisión; telediario; innovación periodística; comunicación interactiva.

\begin{abstract}
Technological innovation engages with new journalism narratives in a context marked by a wide information offer, in which the media try to differentiate themselves and generate more interactivity towards their audiences. This investigation analyses the use of Augmented Reality (AR) as an informative tool on Antena 3 news, in the period between January and April 2019. This Spanish television channel is a pioneer in the implementation of this display technology that recreates immersive situations superimposing physical and virtual realities.
\end{abstract}

The main objective is identifying topics that use AR most, as well as determine their form, interactivity level and main functions. With a clear informative purpose, these resources are mainly associated with news of general interest, normally with a certain prevision or durability. Additionally, this study outlines main characteristics of a surrounding innovative scenography which promotes a closer approach among the anchorman and spectators, contributing to a better information comprehension and assimilation.

Keywords: augmented reality; TV; news; journalism innovation; interactive communication.

1 Leire Azkunaga García es Graduada en Comunicación Audiovisual, Máster en Comunicación Social e Investigadora predoctoral en el Departamento de Comunicación Audiovisual y Publicidad de la Facultad de Ciencias Sociales y de la Comunicación de la Universidad del País Vasco. lazkunaga001@ikasle.ehu.eus, https://orcid.org/0000-0001-8747-2614

Ignacio Gaztaka Eguskiza es Graduado en Comunicación Audiovisual, Máster en Comunicación Social e Investigador predoctoral en el Departamento de Comunicación Audiovisual y Publicidad de la Facultad de Ciencias Sociales y de la Comunicación de la Universidad del País Vasco. igaztaca001@ikasle.ehu.eus, https://orcid.org/0000-0001-9111-7316

Leyre Eguskiza Sesumaga es Graduada en Periodismo, Máster en Comunicación Social e Investigadora predoctoral en el Departamento de Periodismo II de la Facultad de Ciencias Sociales y de la Comunicación de la Universidad del País Vasco. leyre.eguskiza@ehu.eus, https://orcid.org/0000-0002-0308-2545 


\section{Introducción}

Dentro de un escenario mediático con una cada vez mayor oferta informativa, los medios de comunicación buscan diferenciarse y establecer una relación más estrecha con sus audiencias. Es aquí donde la innovación tecnológica y las nuevas narrativas periodísticas se unen para hacer llegar las noticias a unos espectadores cada vez más activos, pero también más exigentes en su consumo informativo. Es lo que Carlos Alberto Scolari denomina "audiencias líquidas" para referirse a los nuevos receptores que "han dejado de estar quietos frente a la pantalla del televisor". Es decir, mantienen todavía un alto consumo audiovisual, pero como consecuencia de la proliferación de dispositivos ven de forma simultánea "cosas diferentes, en diferentes medios y con diferentes modalidades de consumo (2013: 220-222). Frecuentemente, además, las redes sociales se convierten en espacios de debate en los que las audiencias comparten sus opiniones, dando lugar a la televisión social que encuentra su mejor vehículo en los smartphones.

Entre las nuevas herramientas digitales de las que disponen los medios, nuestra investigación pone el foco en la Realidad Aumentada (RA). Esta se presenta como un recurso virtual que cuenta con una "cada vez mayor presencia" en el ámbito comunicativo y "supone un apasionante campo de desarrollo e investigación" (Galán Cubillo, 2008:32). Así lo vaticinaban hace ya más de dos décadas autores como Burdea y Coiffet, afirmando que dichas tecnologías "ya han modificado el modo de pensar y han penetrado fácilmente en la cultura popular" (1996: 17). Desde entonces, la RA se ha afianzado en numerosos campos profesionales y académicos, también en el periodismo, trayendo consigo nuevas formas de contar y modelos de negocio (Meneses-Fernández y Martín-Gutiérrez, 2016: 1-6).

El presente proyecto parte de esta idea para analizar cómo se utiliza la RA en los espacios informativos de televisión. A pesar de que se han realizado algunas exitosas experiencias en diarios y revistas estatales e internacionales como Esquire, The Guardian, Fotogramas o The New York Times, se ha optado por estrechar el foco a la televisión. Esta circunstancia obedece a los datos publicados en el Estudio General de Medios (AIMC, 2018), donde afirman que la televisión continúa siendo el medio más consumido en España, con un porcentaje cercano al $84 \%$, por delante de Internet (79\%), radios (57\%), revistas (29\%) y diarios (22\%).

El objeto de estudio abarca las tres principales ediciones de Antena 3 Noticias (Noticias 1, Noticias 2 y Noticias Fin de Semana). La cadena estatal acumuló la segunda mayor cuota de pantalla durante 2018 (Barlovento Comunicación, 2018), con el 12,3\%, siendo adelantada solamente por Telecinco $(14,1 \%)$. Sin embargo, de acuerdo con los últimos datos aportados por el Análisis del Comportamiento de la Audiencia TV (Barlovento Comunicación, 2019), Antena 3 lidera el consumo de informativos $(15 \%)$ y su edición diaria de sobremesa es la más vista (18\%). Además, el grupo Atresmedia -al que pertenece Antena 3-es pionero en la implantación de la RA desde finales de 2018. Así lo corrobora Mercedes Herrero de la Fuente, al destacar la labor de Atresmedia para "incorporar las nuevas posibilidades de llegar a una audiencia potencial”, en este caso a través de Internet y especialmente de las redes sociales (2017: 523).

En la última década, algunas cadenas como la propia Antena 3 o Televisión Española (TVE) han experimentado con la RA para cubrir acontecimientos informativos de gran interés como las elecciones locales, autonómicas y generales de 2011 en España, en el caso de Antena 3 (Brainstorm Multimedia, 2013), o las elecciones generales de 2016, en TVE (Brainstorm Multimedia, 2018). No obstante, en este caso, no ha sido hasta la apertura de la temporada de informativos 2018/19 cuando Antena 3 ha implantado la RA de forma intensiva. Así lo afirma Santiago González, Director de Antena 3 Noticias, quien indica que mediante esta herramienta se trata de "dar más soporte a la información para contar más y mejor", aunque "siempre como complemento al crecimiento informativo de la cadena" (Antena 3, 2018). Este hecho contrasta 
con el uso puntual de la RA en el ámbito nacional. Medios como la propia TVE, además de otras cadenas autonómicas como TV3, Telemadrid o ETB han seguido esta pauta para relatar acontecimientos como las elecciones generales, sin dar síntomas de continuidad en el uso de esta tecnología en el día a día de sus informativos. A nivel europeo, BBC, RAI, France 2, RTL Germany, TV2 Denmark y Eurosport han aplicado esta tecnología en diferentes ámbitos, además de la información política. Por este motivo, Antena 3 destaca respecto a los demás canales de televisión mencionados.

Santiago González explica que la cadena siempre ha estado a la vanguardia tecnológica en la presentación de nuevos formatos y que continúa adaptándose a los nuevos cambios (Antena 3, 2018). Por este motivo, han implantado la RA en sus informativos. A su vez, Silvio González Moreno, Consejero Delegado del Grupo Atresmedia, contempla la atracción de los nuevos públicos como un "reto", especialmente los menores de 25 años. Por esta razón, han decidido "apostar por nuevas fórmulas para ellos" (KPMG, 2019: 103).

En esta nueva etapa, se ha reestructurado el plató, incorporando una amplia pantalla cóncava, suelo reflectante y un equipo técnico de cámaras robotizadas adaptado a la Realidad Aumentada (Antena 3, 2018). Teniendo en cuenta todo ello, se ha establecido un periodo de estudio comprendido entre enero y abril de 2019, dando lugar a un corpus cercano a los 300 ítems analizados a través de una extensa ficha. Así, se ha efectuado una aproximación exploratoria a esta tecnología que supone un enriquecedor complemento para las informaciones, presentándolas de manera más gráfica y atractiva a la audiencia. A partir de este propósito general se desprenden los siguientes objetivos:

O1. Verificar la existencia de patrones comunes en la selección de los contenidos informativos y en la aplicación de la RA en los telediarios de Antena 3.

O2. Vincular el uso de la Realidad Aumentada a las informaciones de elevado interés social.

O3. Identificar las secciones/temáticas más proclives para la utilización de esta herramienta.

O4. Distinguir en qué medida se utiliza la RA dentro de la narrativa de los telediarios con una función principalmente informativa o como un complemento estético.

O5. Determinar la implicación del/la periodista (presentador/a) en las informaciones con RA.

O6. Conocer si el uso de estas herramientas es independiente o está subordinado a otros elementos de la escenografía virtual.

Una vez clarificados los objetivos del estudio, se han establecido sendas hipótesis sobre las que se ha trabajado a través de la metodología anteriormente detallada:

H1. El uso de la Realidad Aumentada en Antena 3 responde a una lógica previsible y común a todas sus ediciones.

H2. Los acontecimientos con una mayor previsión informativa son más susceptibles a la utilización de la RA.

H3. La presencia del/la presentador/a en las noticias con RA es necesaria ya que ejerce como guía en la interpretación de los datos.

H4. La disposición de la escenografía virtual del plató favorece un alto grado de inmersión en las informaciones con RA.

H5. La RA se utiliza en mayor medida con un elemento para hacer más atractivas las noticias que como herramienta informativa. 


\section{Marco referencial}

\subsection{Realidad Aumentada: Una unión entre el entorno físico y virtual}

Una de las principales cuestiones a las que se enfrenta esta investigación es definir el concepto de Realidad Aumentada. Para ello, se la ha comparado con su principal análogo -el hologramapara tratar de aclarar lo que significa cada concepto y evitar las confusiones del pasado. Michael Bove comprende que los hologramas son "un medio de visualización en el que la difracción se utiliza para reconstruir frentes de onda de luz idénticos a (...) los que se emitirían desde un objeto físico" (2010: 2). Es decir, alteraciones de la luz que, proyectadas desde una infraestructura fija, adoptan las formas que el emisor diseña.

Por otro lado, la definición de la Realidad Aumentada merece una lectura en mayor profundidad. Según Galán Cubillo, el motivo principal de la confusión reside en su definición, pues todavía "no existe una terminología única para definir el fenómeno ni se poseen términos adaptados a la lengua española" (Galán Cubillo, 2008; Väätäjä, Ahvenainen, Jaakola \& Olsson, 2013). Entre otros cabe destacar algunos términos como Realidad Virtual, Entorno Virtual, Inmersión Espacial, etcétera. En cualquier caso, lo que el receptor percibe son contenidos mixtos: la realidad y lo aumentado en superposición (Meneses-Fernández y Martín-Gutiérrez, 2013: 208-209). Sobre estas dos ramas temáticas se desarrolla nuestra definición de RA.

La propuesta de Milgram \& Kishino (1994: 1321-1329), a este respecto, es la más referenciada. En función de la cantidad de objetos virtuales añadidos a la escena real establece una clasificación de cuatro categorías: (1) Entorno Real, (2) Realidad Aumentada, (3) Virtualidad Aumentada y (4) Entorno Virtual. Consideran a esta tecnología como un término medio entre los entornos virtuales y la realidad. Ese espacio que queda es, también, a lo que alude Sánchez García, al decir que la RA es la "inclusión, en tiempo real, de elementos virtuales dentro del mundo físico de forma que el usuario ve a través de una pantalla el mundo real y superpuesto visualiza objetos virtuales" (Sánchez-García, 2019:19).

Ilustración 1. Modelo Reality-Virtuality (VR) Continuum propuesto por P. Milgram y F. Kishino (1994)

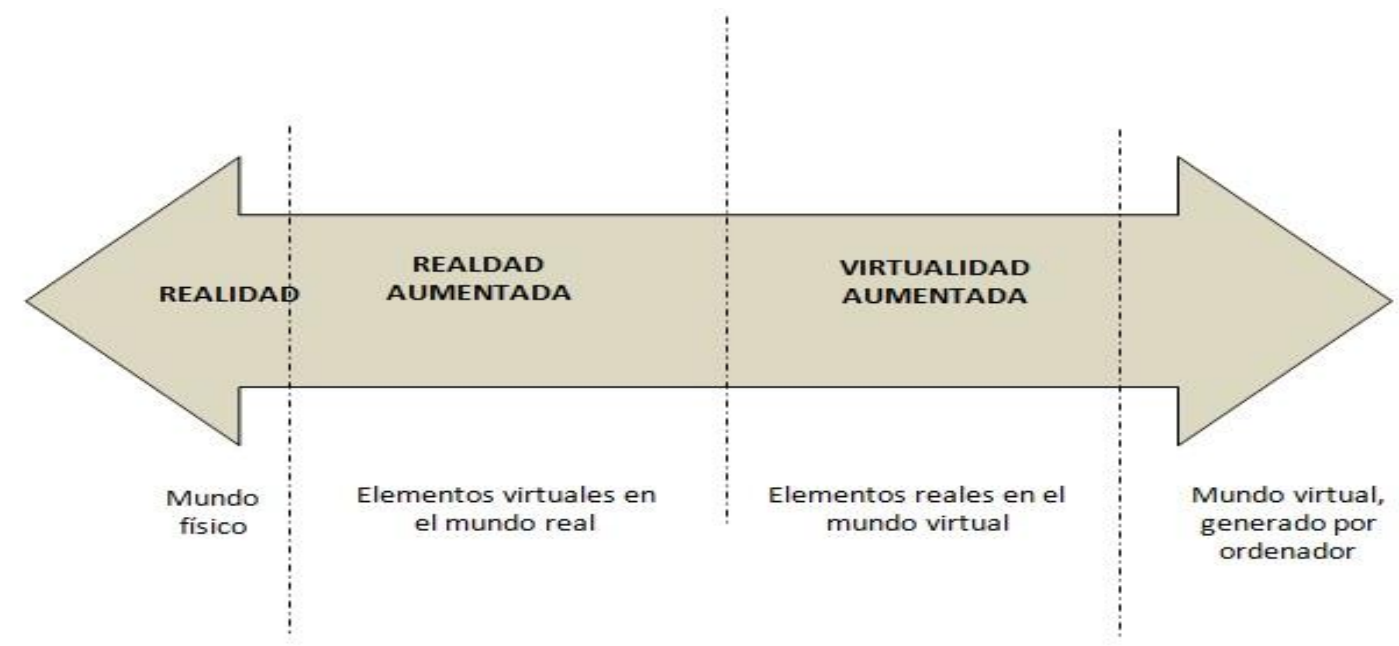

Fuente: Elaboración propia (Milgram \&Kishino, 1994)

En este punto parece necesario señalar las diferencias que separan a la Realidad Aumentada de la Realidad Virtual, pues ambas, aunque semejantes en ciertos aspectos, son completamente diferentes. Siendo la Realidad Aumentada subordinada a la Realidad Virtual, la primera "superpone imagen virtual sobre imagen real", mientras que la segunda se compone de la unión 
de las "Tres I" (Inmersión, Interacción e Imaginación) que proponían Burdea y Coiffet (1996), siendo estas "combinadas con la idea del tracking del punto de vista del usuario en tiempo real" (Galán Cubillo, 2010:13). En otras palabras,

si el entorno del espacio es dominantemente virtual y se le agregan objetos virtuales y reales, se habla de Realidad Virtual; mientras que, si el entorno dominante es real y se le agregan objetos virtuales, se habla de Realidad Aumentada (Abril, 2012: 2).

Abril añade que la RA no sustituye, sino que complementa a la Realidad Física, al "añadir información de interés al mundo real existente" (2012: 1). Una idea a la que se unen MenesesFernández y Martín-Gutiérrez, pues tal y como señalan: "La complementariedad de los contenidos de un escenario real y otro virtual es lo que diferencia la RA de la Realidad Virtual, por lo que no hay que confundirlas" (2013: 208).

En definitiva, se comprende a la Realidad Virtual (RV) como la matriz de la que nace la Realidad Aumentada. En este punto, es importante conocer una característica clave de esta innovación tecnológica: la interactividad entre el objeto, la RV, y el sujeto -espectador- (Burdea y Coiffet, 1996: 23-24). La interactividad ayuda a la sensación de inmersión que experimenta el usuario al participar en la acción. "Los usuarios no se limitan a ver y a manipular objetos Figuras en la pantalla, también pueden tocarlos y sentirlos táctilmente" (Burdea \& Coiffet, 1996: 24).

\subsection{Las posibilidades de una herramienta en constante evolución}

Los ensayos pioneros con RA datan de finales de los 60 y principios de los 70. Estos primeros intentos motivaron "posibilitar un tipo de visión que permitiera superponer, en la pantalla de un dispositivo, datos, información, imágenes fijas o en movimiento, animación y locuciones, a lo observado a simple vista, es decir, la visión primaria” (Meneses-Fernández y MartínGutiérrez, 2013: 208). La evolución de la RA comprende cuatro etapas, diferenciadas cronológicamente según los avances tecnológicos. Para este apartado resulta fundamental el trabajo académico firmado por John V. Pavlik y Frank Bridges bajo el título The Emergence of Augmented Reality (AR) as a Storytelling Medium in Journalism (2013).

La primera fase se caracteriza por el diseño inicial de la investigación y el desarrollo de la tecnología de RA, ajena al ámbito periodístico. En este momento, su campo de aplicación se circunscribe a la ingeniería aeroespacial. Esta etapa se alargó hasta la década de los 90.

Segundo periodo implicó una evolución temprana de la RA, en la que algunas de sus múltiples posibilidades fueron puestas a prueba. Fue aplicada a una amplia gama de actividades humanas que incluían la medicina, la comunicación y las artes. Durante este tiempo, la RA seguía formando parte, en gran medida, del ámbito de la investigación. Aunque sus primeros sistemas móviles se iniciaron entonces, la mayoría eran a menudo complejos y poco prácticos. Posteriormente, la tercera fase se distingue por varias cualidades destacables como la miniaturización, comercialización y disponibilidad de la RA en dispositivos móviles (Pavlik \& Britges, 2013: 7).

En consecuencia, se produjo un aumento de su uso entre distintas organizaciones y medios de comunicación, quienes empezaron a adoptar este tipo de tecnología para fines comunicativos y estratégicos. Los citados académicos anticipaban que en un futuro cercano se producirá una cuarta etapa, "aunque su creación será difícil de predecir" (Pavlik \& Britges, 2013: 7). Por un lado, proponen que la RA será plenamente implementada en el ámbito comunicativo como medio narrativo. También sugieren que se "integrará ampliamente como una herramienta rutinaria en las organizaciones de noticias, tanto como la fotografía y los Figuras informativos" (Pavlik \& Britges, 2013: 7). 
Ilustración 2. Etapas de desarrollo de la RA propuestas por J. Pavlik y F. Bridges (2013)

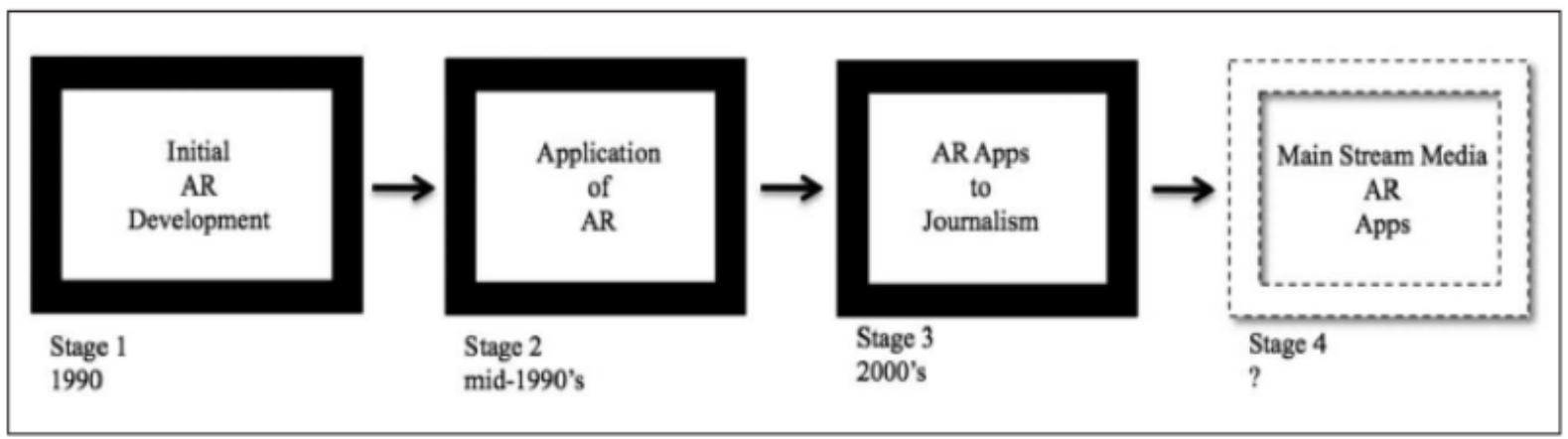

Fuente: The Emergence of Augmented Reality (AR) as a Storytelling Medium in Journalism

(Pavlik \& Bridges, 2013)

En cuanto a los rasgos o características que definen la RA, Azuma atribuye tres elementos principales: la mezcla de lo real y lo virtual, la interactividad en tiempo real y el registro tridimensional (Meneses-Fernández y Martín-Gutiérrez, 2013: 214). Destacamos también la clasificación que realizan Parhizkar, Al-Modwahi, Lashkari, Bartaripou y Babae (2011), diferenciando aplicaciones de escritorio, para móviles y web. Fermín-Lobo (2013), por su parte, identifica otros elementos comunes como la ubicuidad y la información en 3D.

Para comprender el funcionamiento técnico de la Realidad Aumentada es conveniente acudir a Daniel Abril. El autor detalla que esta tecnología integra señales captadas del mundo real (vídeo y audio) con señales generadas por computadores (objetos Figuras tridimensionales y bidimensionales) y las hace corresponder para construir nuevos mundos coherentes, complementados y enriquecidos (Abril, 2012: 2). Por esta misma línea, Caldera-Serrano enumera los diferentes dispositivos que son capaces de proyectar la RA y añade que "todos consisten en estrechar la distancia que separa el mundo virtual con el real" (2014: 645):

- Head-mounted displays: dispositivo colocado en la cabeza o en un casco. Obtiene la información por medio de cámaras. Utilizados tanto para RV como para la Realidad Mixta.

- Computadores personales y laptops: desplazados actualmente por los móviles, fueron los primeros utilizados.

- Smartphones y Tablets: dispositivos más usados para RA actualmente, debido a que sus sensores aportan información sobre geolocalización del usuario.

- Pantallas espaciales: dispositivos ópticos, vídeo proyectores, etc.

- Guantes de gestos: el usuario puede manipular objetos virtuales mediante guantes con sensores.

- Dispositivos para videojuegos: originalmente los dispositivos de RA fueron creados para videojuegos, implementados por Wii (Nintendo), Move (Sony PS3) o Kinect (Microsoft).

A modo de cierre, el motivo principal que ha impulsado a las televisiones a implantar la RA en sus espacios informativos son las ventajas visuales y posibilidades estéticas que ofrece, así como sus innumerables opciones de optimización de la información. Desde el ámbito de la investigación se ha reflexionado sobre esta dupla de avances; es decir, lo ventajoso de la RA con respecto a lo estético, por un lado, y la mejora en lo concerniente a la información, por el otro. En este sentido, la RA aplicada al medio televisivo sirve para explorar nuevos métodos, tanto formales como narrativos, para transmitir el contenido informativo a los espectadores. Esta tecnología ha ampliado el abanico de posibilidades a la hora de narrar lo sucedido desde un prisma visual más concreto, más físico y, por ende, más presencial. A pesar de los avances 
en las diferentes áreas industriales y económicas, Drascic y Milgram (1996) subrayaron, desde un comienzo, la importancia de trabajar sobre las debilidades de estos sistemas de cara a su exitoso desarrollo futuro.

\subsection{Un recurso multidisciplinar}

Es más que importante señalar los cambios que en el futuro le deparan a la RA. Más allá de las innovaciones narrativas que esta tecnología aportará al mundo de la información, ya hay voces que auguran que la RA sustituirá a los smartphones mediante sus propios dispositivos (Hill: 2011). No obstante, antes de que esto ocurra, son estos dispositivos móviles los que contribuyen a que la RA pueda explotar todas sus posibilidades.

Varios autores han identificado los campos de innovación esta tecnología, así como su trayectoria presente y futura. Höllerer y Feiner remarcan que, a pesar de la gran cantidad de investigaciones y avances que se están realizando, aún no se ha terminado de alcanzar el punto en el que la RA sea fácilmente adoptada para el consumo de masas (2004: 34). Ilic y Flesich, por su parte, analizan la función que la RA está adquiriendo como puente entre Internet y "otros factores de forma alternativos al smartphone como gafas, relojes, guantes, etcétera" (2016: 2). En la línea de Hill, los autores pronostican que los smartphones serán sustituidos por dispositivos de RA muy concretos que combinarán ciertos elementos virtuales para mejorar la experiencia de la realidad física. Aun así, ambas tecnologías permanecen unidas hoy en día, siendo objetos complementarios en áreas como las bibliotecas públicas, los museos y las instituciones artísticas (Ashford, 2010).

Continuando con esta idea, la Fundación Telefónica (2011) comprendía, hace ya una década, que la RA comenzaba a explotar todas sus posibilidades de la mano de los dispositivos móviles. En este sentido, su carácter versátil y su amplio campo de aplicación son unas de sus mayores fortalezas, siendo cada vez más común encontrar la RA en ámbitos tan heterogéneos como el marketing, el turismo, la medicina o los procesos de búsqueda. Al mismo tiempo, ha servido para mejorar la eficacia en los procesos de producción de la industria aeronáutica (Caudell y Mizell, 1992) y la navegación GPS (Grewal, Andrews y Bartone, 2013).

En el campo educativo, por ejemplo, las TIC han supuesto una renovación de la enseñanza tradicional (Spector, Merrill, Elen \& Bishop, 2014). En concreto, la RA ha contribuido a la creación de nuevos métodos de enseñanza como complemento a las herramientas tradicionales (Kerawalla, Luckin, Seljeflot \& Woolard, 2006; Thorton, 2010; Fombona, Pascual y Madeira, 2012; Vale-U-Lan, 2012; De la Torre-Cantero, Martín-Dorta, Pérez, Carrera y González, 2013; Martín, 2015; Barroso y Pérez, 2016; Yilmaz \& Gotkas, 2017). Son de mencionar el proyecto Magic Book, del grupo activo HIT de Nueva Zelanda, cuyo objetivo era comprobar si resultaba más sugestiva la lectura y el aprendizaje de los contenidos entre los alumnos a través de imágenes virtuales. Por otro lado, el Massachusetts Institute of Technology (MIT) y Harvard desarrollan actualmente aplicaciones de RA para crear contenidos lúdicos virtuales en smarpthones (Abril, 2012).

En el área comunicativa comienza a emplearse también de manera habitual en campos como la publicidad, el marketing en línea o el street marketing, y su uso se ha extendido recientemente, sobre todo como un complemento en los medios impresos y televisivos (Ruiz y Polo, 2012; Meneses-Fernández y Martín-Gutiérrez, 2013; Infante, Jácome y Chicaiza, 2016; OteguiCastillo, 2017). Cada vez más países consideran la RA como una forma de aumentar su competitividad, ofrecer contenidos de forma original y diferenciarse de sus iguales (MenesesFernández y Martín-Gutiérrez, 2013: 207-208). La revista estadounidense Esquire fue pionera en 2009 al implementar la RA en prensa. Igualmente, destacables resultan otros ejemplos 
internacionales como los de Wallpaper, The Daily Telegraph, The Times y The Guardian (Reino Unido); The New York Times, USA Today, Wall Street Journal, Financial Times y The Boston Globe (EEUU); Il Tireno (Italia); SZ MAGAZINE (Alemania); Elle y Fotogramas (España).

En este sentido, son varios los autores que han desarrollado estudios sobre la RA en el ámbito periodístico. Vargas Alzate (2012) analiza tres medios impresos internacionales: El tiempo, Daily Telegraph de Australia y El País (edición Colombia). Los ya citados Meneses-Fernández y Martín-Gutiérrez (2013), por su parte, evaluaron la viabilidad y repercusión como consecuencia de utilizar la RA en diversos diarios y revistas españolas y extranjeras. En una investigación posterior realizada en 2016, los mismos autores trataron de conocer si la RA ofrecía una mayor cercanía a los lectores. Los resultados indicaron que esta herramienta renovaba y actualizaba los perfiles profesionales y exigía a los periodistas adquirir nuevas competencias, al tiempo que estimulaba la creatividad en los contenidos. Otros académicos como Parra, Edo y Marcos (2017) centran su atención en analizar el uso que los medios españoles -el diario El País, a través de su publicación El Viajero, y la revista Fotogramasestán realizando de esta innovación.

En la misma línea, Väätäjä et al. (2013) analizan la percepción de los usuarios por medio de la presentación de cinco noticias locales en RA. En un contexto más amplio, pero sin abandonar la comunicación, John Pavlik (2001) realiza un repaso sobre las principales innovaciones experimentadas por el periodismo en la última década, marcada por la caída de audiencias de los medios impresos y por el incremento de la visualización de informativos en los dispositivos móviles y, en menor medida, en televisión. Este es el punto de partida del Project 2020 desarrollado por la redacción del The New York Times, que plantea una total transformación en su modelo de negocio, sus rutinas y sus narrativas periodísticas para adaptarse al nuevo contexto mediático y acercarse a su audiencia. Entre los principales retos menciona la necesidad de hacer un periodismo más visual que aproveche las potencialidades de la Realidad Virtual (2017).

\subsection{Transformación de los medios de comunicación en un contexto hiperconectado}

Los medios de comunicación, en constante cambio, están mutando hacia una etapa que algunos expertos han denominado Mediamorfosis (Fidler, 1998), en la que la RA trae consigo una modernización y "aporta complementariedad a contenidos impresos que no logran el impacto deseado por los emisores ni un efecto comunicativo satisfactorio en los destinatarios" (Meneses-Fernández y Martín-Gutiérrez, 2016: 6). Así, no sólo se han visto alteradas las distintas fases de producción de los contenidos informativos, sino que se han incorporado nuevos perfiles profesionales (Galán-Cubillo, 2008). De la misma opinión es Joao Canavilhas (2013), quien argumenta que estamos ante un nuevo ecosistema mediático marcado por la transformación en los hábitos de consumo informativo y por la llegada de nuevos productores y distribuidores. Por ello, se plantea la necesidad de identificar esas nuevas actividades periodísticas que deberían realizarse en las redacciones. Pavlik \& Bridges (2013: 5) detectan las cuatro áreas principales del oficio periodístico y de los medios de comunicación que se han visto modificadas:

- Rutinas de trabajo: Se alteran las rutinas de recopilación, edición y producción de las noticias, pues se busca una actualización continua y una presentación atractiva para una audiencia cada vez más alejada de los medios tradicionales.

- Modelos de negocio: Se reestructura la entrega de noticias, reduciendo en gran medida su costo y transformando el modelo de negocio. Se construye "un modelo financiero y de 
negocio sostenible para producir periodismo de calidad en un entorno global, interconectado y móvil".

- Relación con las audiencias: Se aspira a facilitar una vinculación más estrecha entre ciudadanos y medios.

- Contenidos: La finalidad de estas nuevas herramientas es atraer al espectador y mostrarle innovadoras formas de visionado de contenidos. Así, "la RA emerge como una tecnología que puede transformar los métodos tradicionales de storytelling en el periodismo".

Este nuevo contexto se caracteriza por un acceso global a la información, la creación de contenidos multimedia y/o interactivos, y una actualización continua (Pavlik, 2001). De este modo, el actual medio televisivo camina hacia una televisión social, multiformato y multisoporte. "La televisión es ahora mucho más que un canal de difusión de información, se ha convertido en un lugar para el intercambio" (Caldera-Serrano, 2014: 644). Volviendo al objeto de estudio específico de la investigación, Galán Cubillo (2008) elabora en su trabajo un glosario sobre los principales conceptos empleados por investigadores y profesionales. El autor se decanta por el término Escenografía Virtual para denominar el escenario creado en televisión por medio del chroma key y las pantallas que decoran el plató. En sus palabras, la RA es un elemento más de dicha escenografía y la sitúa como un paso intermedio entre la Realidad Virtual y la Realidad Física. Si bien el plató ha perdido su papel hegemónico como único elemento que configuraba la puesta en escena, herramientas como la RA han impulsado una nueva forma de hacer periodismo, el llamado Periodismo Inmersivo, cuyo objetivo es fomentar la experiencia informativa en primera persona entre los espectadores (Sirkunen et al., 2016).

Son múltiples las referencias académicas (Barabas, 2014; Pavlik \& Bridges, 2013; Sirkkunen, Väätäjä, Uskali \& Rezaei, 2016; Meneses-Fernández y Martín-Gutiérrez, 2016) que reafirman el gran potencial existente en el "matrimonio entre la RA y el Periodismo", puesto que ésta posee "un potencial sin precedentes para reproducir múltiples aspectos de la visión natural" (Barabas, 2014: 31). En este sentido, Pavlik \& Bridges destacan las oportunidades que ofrece para la narración y difusión de noticias: "El storytelling en RA representa una oportunidad sustancial para el periodismo, y constituye una manera de enganchar a los lectores a los contenidos e historias de una manera significativa" (2013: 17).

El propósito principal de este tipo de tecnología es “entretener y acercar al público los contextos noticiosos" (Meneses-Fernández y Martín-Gutiérrez, 2016:3), así como conectar con historias reales y empatizar con sus protagonistas (Väätäjä et al., 2013: 968). Sin embargo, Pavlik \& Bridges plantean que su uso se extenderá en mayor medida a las softnews, es decir, a las noticias ligadas al entretenimiento y la cultura o los deportes, y no tanto a contenidos informativos de mayor envergadura (2013: 19).

Al tratarse de un instrumento todavía en desarrollo, la RA plantea ciertos desafíos futuros por parte de productoras y medios (Pavlik \& Bridges, 2013; Sirkkunen et al., 2016). Por un lado, aún existen limitaciones técnicas para desarrollar este tipo de tecnologías, siendo necesaria la apuesta por la creación de un nuevo modelo de negocio. Asimismo, la gran cantidad de contenidos multimedia e interactivos generados requieren de un hardware y una base de datos adecuados para manejar las necesidades de programación y gestión de conocimiento. Por último, los autores plantean la necesidad de formar a los profesionales y al propio público para disfrutar de una experiencia plena. 


\subsection{Noticiabilidad y valores/noticia: Factores de selección de contenidos informativos en los medios de comunicación}

En la línea de lo expuesto hasta el momento, resulta evidente que la llegada de Internet ha revolucionado la manera en la que transmitimos y recibimos información. En este novedoso escenario multimedia, multipantalla e interactivo descrito previamente sigue cobrando especial relevancia la figura del periodista, como gatekeeper o encargado de la selección de los acontecimientos que transforman en noticias.

De esta manera lo expone Mauro Wolf en La investigación de la comunicación de masas (1987), obra de referencia donde define el concepto de noticiabilidad como los elementos a través de los que se gestionan los acontecimientos que se convertirán en noticias (p. 119). Sobre esta idea describe los valores/noticia (news values) como un componente de la noticiabilidad que ayuda a determinar qué hechos son considerados "suficientemente interesantes, significativos, relevantes" (p. 119).

Estos valores operan de forma complementaria, es decir, funcionan de manera conjunta mediante distintas relaciones y combinaciones, además de estar presentes en todas las fases de producción de contenidos informativos, y no solo en la selección (p. 120). Por esta razón, Wolf puntualiza que no se trata de "criterios fijos", sino que poseen una "naturaleza dinámica" que los hace variar a lo largo del tiempo (p. 121). En otras palabras, hablamos de unas "reglas prácticas que incluyen un corpus de conocimientos profesionales que implícitamente, y a menudo explícitamente, explican y dirigen los procesos de trabajo en la redacción" (p. 120). La clasificación de estos elementos para la selección de contenidos informativos propuesta por el autor distingue cinco categorías: (p. 122-132)

- Criterios sustantivos: Esencialmente giran en torno a la importancia y el interés de la noticia. Aquí encontramos el grado y nivel jerárquico de los protagonistas, el impacto sobre la nación y el interés nacional -relacionado con la proximidad geográfica y cultural- o la cantidad de personas implicadas. También resulta determinante la importancia de este hecho con respecto a la evolución futura de una determinada acción.

- Criterios relativos al producto: Está asociado, entre otros, a las posibilidades técnicas y organizativas del medio, así como a la novedad y brevedad del mismo. Esto se traduce en que "lo que altera la rutina es noticia", y los acontecimientos negativos suelen serlo con mayor frecuencia. También hablamos de la composición equilibrada del telediario en su conjunto, relacionándolo con la necesidad de atraer y mantener el interés de la audiencia.

- Criterios relativos al medio: Disponibilidad de "buen material visual", siendo significativo tanto desde el punto de vista técnico como de contenido. Por otro lado, también es destacable la frecuencia, entendida como el tiempo necesario para que el hecho adquiera sentido. Wolf señala, a este respecto, que los medios radiotelevisivos priman los acontecimientos puntuales y únicos, concluidos en un breve espacio de tiempo. En tercer lugar, también se valoran los límites espacio-temporales del propio telediario.

- Criterios relativos al interés del público: Destaca la importancia de los hechos que permiten una identificación por parte de la audiencia, de las llamadas noticias servicio, y de las "noticias ligeras" (non-burdening stories).

- Criterios relativos a la competencia: Hablamos de los casos en los que un medio logra una primicia, de las expectativas generadas al suponer que un acontecimiento será seleccionado por el resto de medios, o de las pautas de comportamiento marcadas por los medios o modelos de referencia. 


\section{Metodología}

A fin de lograr los propósitos planteados, se ha diseñado una metodología mixta que combina el análisis cuantitativo y cualitativo del objeto de estudio. Para ello, se ha seleccionado una muestra que abarca las tres principales ediciones de los telediarios emitidos en la cadena de televisión analizada: Noticias 1 -informativo diario, en horario de mediodía-, Noticias 2 telediario nocturno- y Noticias Fin de Semana -en su edición de mediodía y nocturna-. Cabe señalar que, al tratarse de espacios informativos claramente diferenciados del propio telediario, los contenidos deportivos (Deportes Antena 3) han quedado fuera del proceso de análisis. Pueden encontrarse, sin embargo, algunos ejemplos de noticias relativas a la temática deportiva, pero siempre corresponden al citado noticiario.

Con todo, se establecido un periodo de análisis que discurre entre el 1 de enero y el 30 de abril de 2019, generando un corpus de estudio que alcanza las 295 piezas informativas: 118 corresponden a Noticias 1, 149 a Noticias 2, y 28 a Noticias Fin de Semana. Una vez identificados todos los casos en los que se han empleado los contenidos de RA, se ha procedido al registro, clasificación y archivo de dichos contenidos, disponibles temporalmente en la plataforma digital de visionado del grupo Atresmedia (Atresplayer).

Posteriormente se ha realizado un estudio en profundidad de estas piezas mediante una ficha de análisis que cuenta con un total de 19 categorías y que ha sido elaborada ex profeso de acuerdo a los objetivos del proyecto. Los contenidos se dividen en tres bloques referidos a la identificación de la noticia (4 ítems), su ubicación dentro del telediario (5 ítems), y las características del contenido (10 ítems). A su vez, cada uno está formado por subcategorías que permiten efectuar un examen más pormenorizado.

- Registro de identificación: Incluye el número de ficha, medio de comunicación, fecha y edición del informativo (Noticias 1, Noticias 2, Noticias Fin de Semana Mediodía o Noticias Fin de Semana Noche).

- Ubicación de la pieza informativa: Aborda cuestiones como la sección a la que pertenece, su temática -breve identificación del suceso con palabras clave-, la duración del contenido y de la noticia dentro del informativo, su ubicación temporal -al inicio, en la mitad o al final del telediario-, o la previsión con la que cuenta el acontecimiento.

- Uso de la Realidad Aumentada: Esta área se completa con subcategorías específicas relativas a la relación con los distintos elementos de la escenografía virtual, a la forma que adopta o a los elementos que lo acompañan. De igual manera, se han tratado de clarificar la tipología y funciones que cumplen estos elementos. Para esta labor se ha tomado como base la aportación algunos autores de referencia en la materia (Burdea y Coiffet, 1996; Azuma, 1997; Meneses-Fernández y Martín-Gutiérrez, 2013: 217). La inmersión, omnidireccionalidad, realismo, interactividad, creatividad, interacción o la capacidad informativa son algunos de los aspectos atribuidos a esta tecnología. A continuación, se detalla la naturaleza de todos los apartados:

- Tipología: De menor a mayor grado de inmersión y movimiento, se distinguen los contenidos estáticos, los móviles y los envolventes.

- Presencia del/la presentador/a junto al contenido en RA.

- Relación con la pantalla: Determina si existe una superposición del elemento en RA con respecto a la imagen de la pantalla, utilizando esta como fondo, o si, por el contrario, no existe ninguna interacción. 
- Inmersión del presentador/a: Indica si este/a se encuentra 'dentro' del escenario (inmersión) o se sitúa delante/detrás/al lado.

- Interacción entre el presentador/a y el contenido en RA: De menor a mayor grado se clasifican en no interacción, interacción limitada -el/la presentador/a lo menciona, pero no hace uso de él para ampliar la información-, e interacción elevada -se utiliza como un recurso explicativo activo-.

- Presencia de datos junto al contenido en RA

- Objetivo principal: En términos generales, se trata de discernir si cumple principalmente una función informativa o se limita a ser un elemento estético que acompaña a la noticia.

- Función/funciones: En relación con el punto anterior, esta pregunta abierta amplía el propósito con el que se utiliza la RA en los ítems analizados. Posteriormente se ha llevado a cabo una reagrupación y categorización de las respuestas registradas, dando lugar a las siguientes subcategorías: ampliación de datos, ubicación del espectador, transición entre noticias, y función estética.

- Forma: Escenario (lugar), animal, persona, vehículo, elemento arquitectónico (edificio), rótulo, Figura (logotipo), objeto.

- Elementos que lo acompañan: Se ha identificado el contenido que sucede a la RA en la narración de la noticia. Puede tratarse de una conexión en directo, vídeos, datos proyectados en la pantalla, intervención del/la presentador/a en el plató, u otra cuestión (especificar).

El extenso volumen de datos obtenidos ha sido codificado y procesado mediante el software estadístico SPSS, el cual ha posibilitado la posterior interpretación cualitativa de los resultados y el establecimiento de una serie de pautas o elementos comunes en la utilización de esta tecnología virtual por parte de Antena 3.

\section{Análisis de los resultados}

En líneas generales, es posible afirmar que Noticias 2 es la edición que cuenta con un mayor número de noticias con RA, siendo estas 149 con respecto al total de 295 . Esto supone que el $50 \%$ de las informaciones se sitúan en el telediario nocturno. Le sigue a poca distancia Noticias 1, con 119 ítems (40\%). Y, por último, muy alejada del resto, se encuentra Noticias de Fin de Semana, con 28 noticias, es decir, apenas un 10\% del total. Esta clara distancia de las dos ediciones diarias con respecto a su homóloga de los fines de semana debe ser tenida en cuenta a la hora de interpretar los resultados de las categorías que a continuación se presentan.

Otro de los aspectos analizados han sido las secciones o temáticas más susceptibles a la utilización de la RA. En esta categoría se aprecia el predominio de la categoría de Sociedad y Sucesos, el 35\% del total. También se sitúan en las primeras posiciones, aunque a cierta distancia, las secciones de Internacional (27\%) y Política (26\%), prácticamente empatadas. 
Figura 1. Contenidos de Realidad Aumentada creados por Antena 3 Noticias

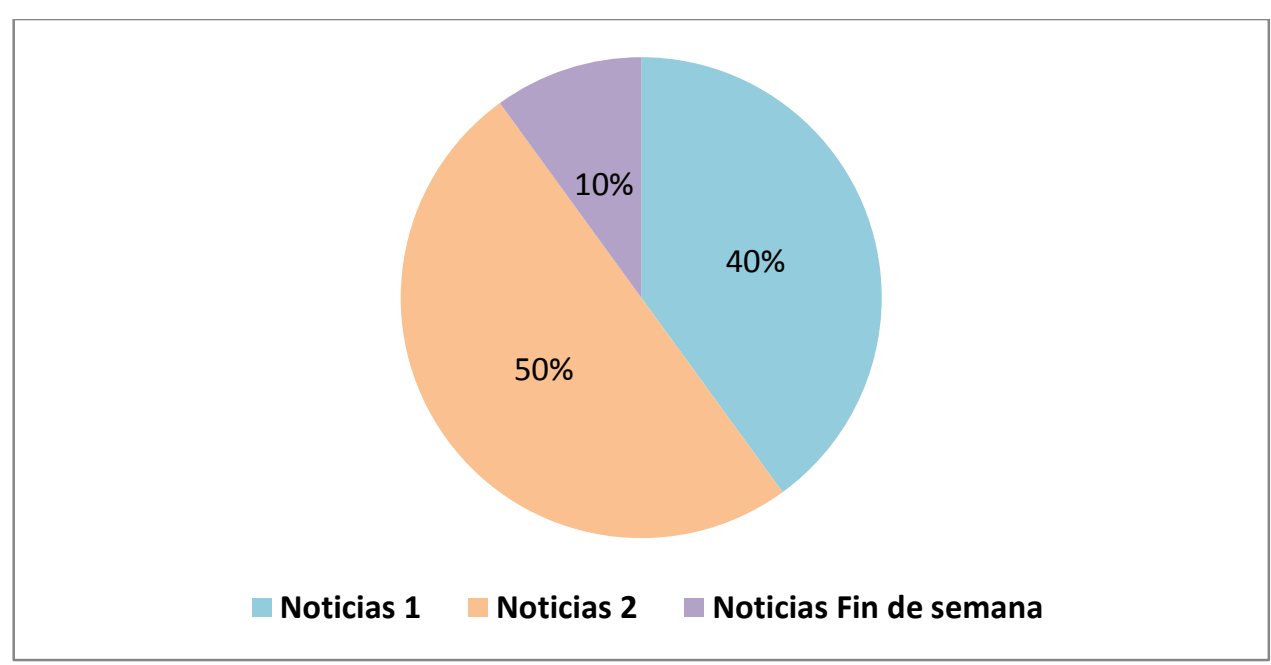

Fuente: Elaboración propia.

Los datos correspondientes a cada edición muestran que Política (37\%) y Sociedad (38\%) están prácticamente empatadas en Noticias 1, evidenciando el peso de ambas secciones. Las otras categorías quedan relegadas. En Noticias 2, no obstante, es la sección de Internacional la que encabeza la lista con un 40\%, sacando una ventaja de ocho puntos a Sociedad y Sucesos, sección que la precede. El resto quedan muy alejadas. Por último, durante los fines de semana, parece que las noticias con mayor presencia de RA son las relacionadas con Sociedad y Sucesos (39\%) o Política (32\%).

Figura 2. Secciones más susceptibles al uso de la RA (distribución por ediciones)

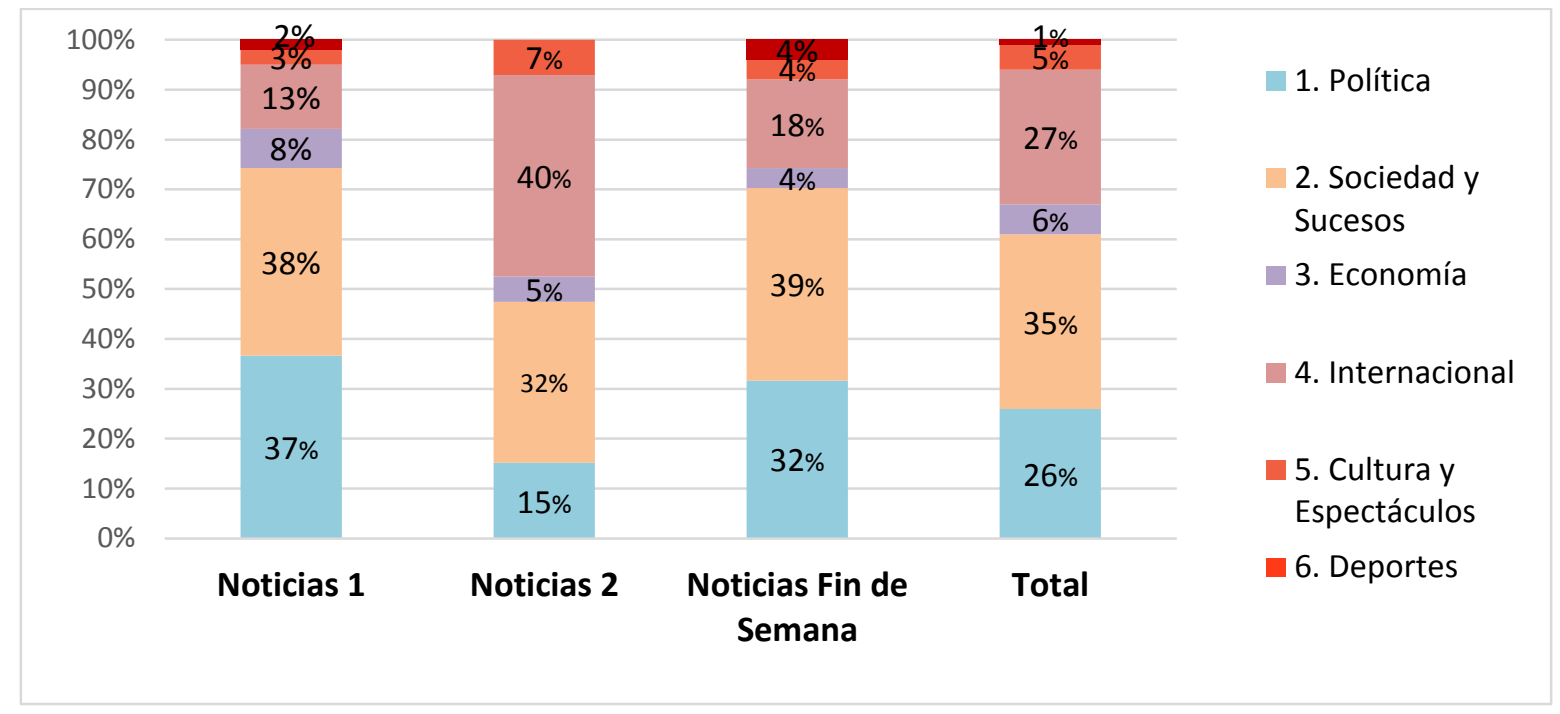

Fuente: Elaboración propia

Por otro lado, respecto al factor de la previsión, podemos decir que las tres ediciones muestran que las noticias relacionadas con acontecimientos previsibles en la agenda informativa (Elecciones Generales, Brexit, huelgas de taxistas, Conflicto en Venezuela, etc.) han sido más susceptibles de ser portadoras de RA. En Noticias 1 los porcentajes son prácticamente parejos, ya que las informaciones con previsión ocupan el 53\% mientras que las imprevistas son el 47\%. En Noticias 2, la brecha es mayor, siendo un 58\% la información prevista y un $42 \%$ la que no. 
Por último, en Noticias Fin de Semana es donde se encuentra una mayor diferencia: lo acontecido previsiblemente supone el $68 \%$ de espacios con RA, siendo hechos fortuitos en tan solo un $32 \%$ de los casos.

En lo que respecta a la duración de los contenidos en RA de cada noticia, la media se extiende hasta los 15 segundos, mientras que la duración media de las informaciones en las que se ha empleado RA alcanza los 3 minutos. Esto supone que el espacio que ocupa la RA dentro de la narración de cada noticia, es de una media de 15 segundos sobre un total de 180, en otras palabras, un $8 \%$.

Figura 3. Ubicación en el telediario de los contenidos en RA (distribución por ediciones)

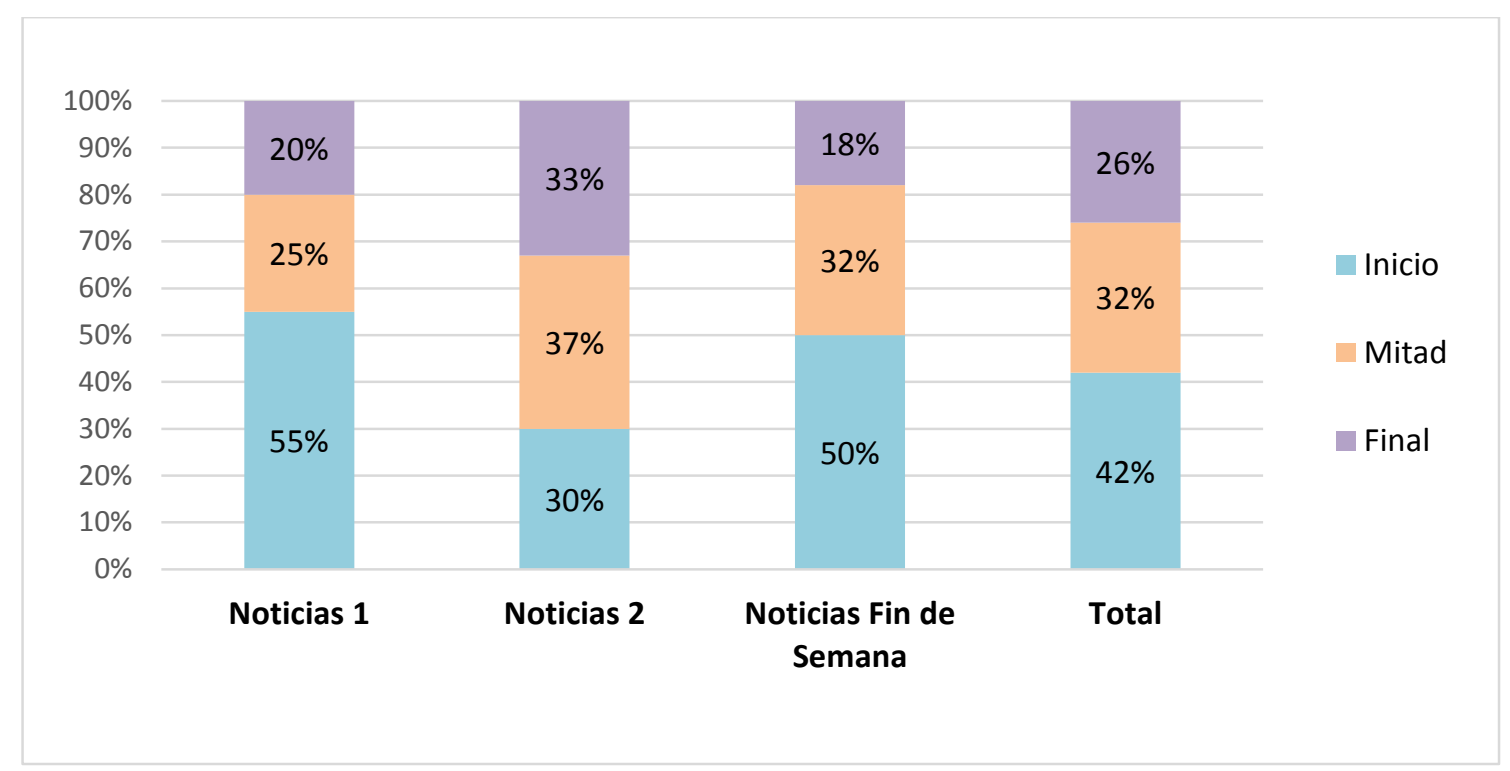

Fuente: Elaboración propia.

En el $42 \%$ de los casos, las noticias en las que se ha aplicado la RA están situadas al comienzo del noticiario. Esto sugiere que los acontecimientos más importantes del día son más susceptibles de ser complementados con RA. La clasificación mantiene una lógica, pues el segundo tercio de cada edición está situado también en el segundo puesto del ranking de noticias con RA, con un $32 \%$. Por ello, es en el final de cada noticiario donde se encuentran menos informaciones en las que se aplica esta tecnología (26\%)

En cuanto a la tipología de los elementos en RA presentes en los noticiarios de Antena 3, se distinguen tres: estáticos, móviles-realizan algún tipo de movimiento o se desplazan por el plató-, y envolventes-llenan por completo el espacio del plató de televisión y el presentador o presentadora se desplaza momentáneamente por ellos-. En general, existe una clara preferencia por el uso de los de tipo estático, teniendo en cuenta que en los tres telediarios destacan los contenidos fijos con un $63 \%$, frente a un $34 \%$ de los contenidos móviles, o sobre un escaso $3 \%$ de los denominados envolventes. 
Ilustración 3. Capturas de contenidos envolventes creados por Antena 3 Noticias

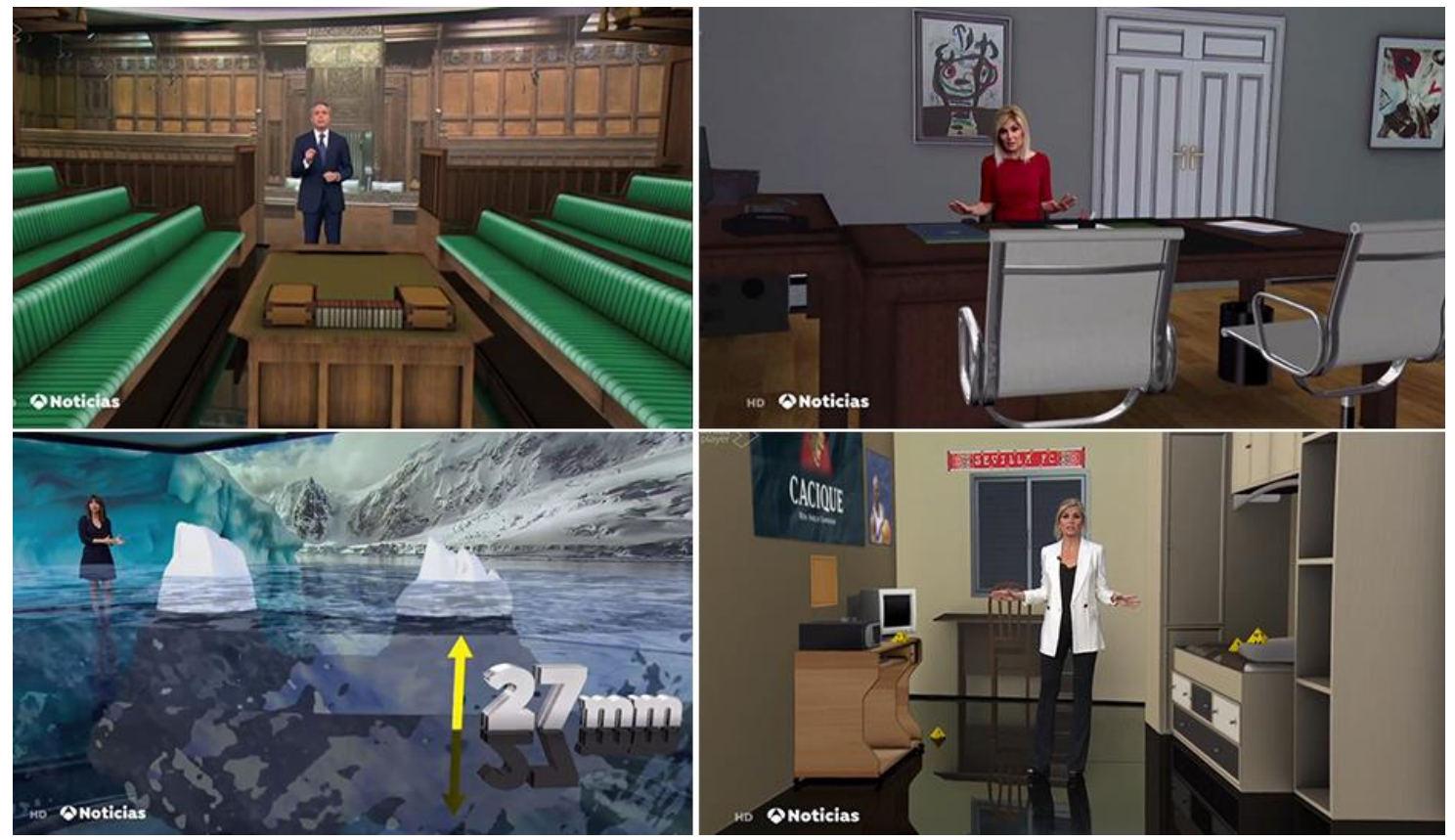

Fuente: Antena 3

También es importante señalar que se utilizan de manera similar los diferentes tipos de recursos a lo largo del periodo analizado, es decir, de enero a abril de 2019, con una clara preferencia por los de tipo estático. El escaso uso de los envolventes es recurrente y no alcanza el $2 \%$ en ninguno de los meses salvo en marzo, cuando obtiene un 7\% sobre el total. En lo referente a las ediciones, se puede observar que tanto en Noticias 2 como en Noticias Fin de semana predominan los recursos estáticos de RA, con un $76 \%$ y un $89 \%$, respectivamente. En el caso de Noticias 1 presentan un peso similar los contenidos móviles (55\%) y los estáticos (41\%). En cuanto a los contenidos envolventes resultan anecdóticos en todos los telediarios, pues no llegan a superar el 5\% y en el caso Noticias Fin De Semana no tienen ninguna presencia en los cuatro meses analizados.

Figura 4. Tipología de contenidos de Realidad Aumentada (distribución por ediciones)

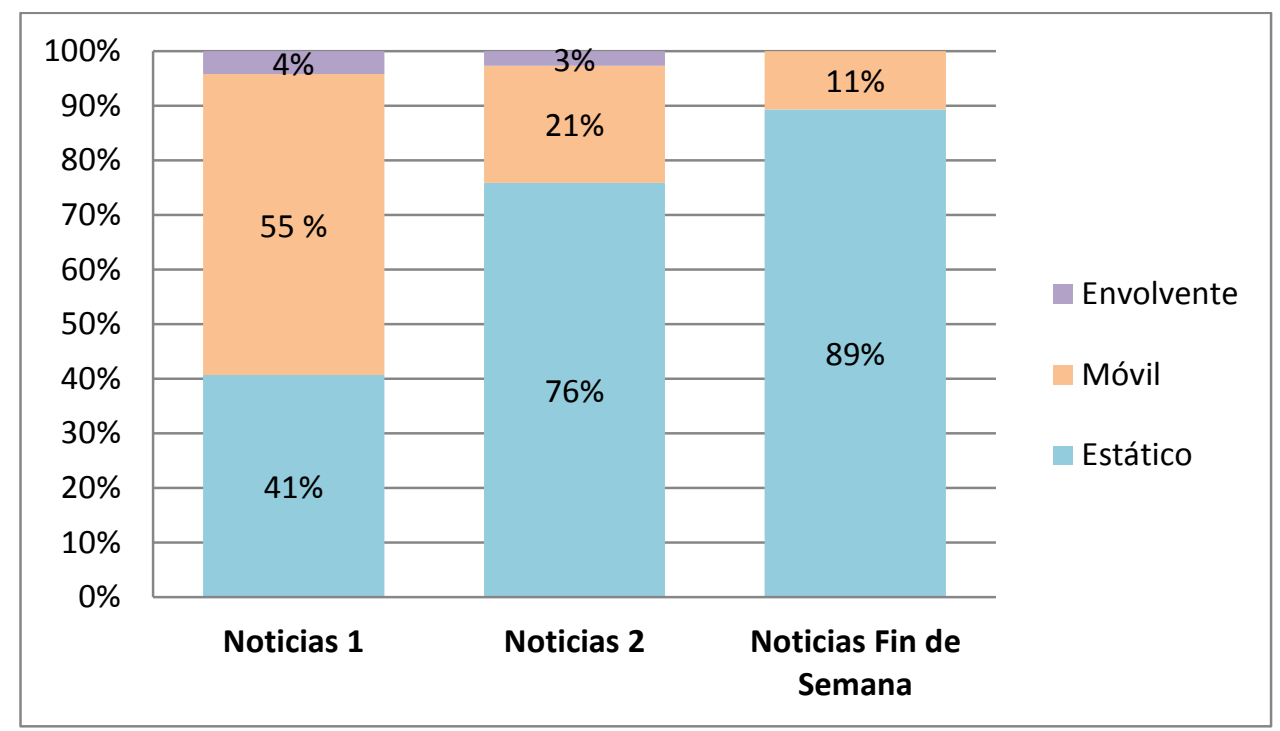

Fuente: Elaboración propia. 
Por otro lado, el $90 \%$ del total de los contenidos analizados son conducidos o explicados por medio de la figura del/la presentador/a. Además, la presencia del/la periodista en las noticias obtiene resultados similares en las tres ediciones. De este modo, se erige como una figura clave para la presentación de estas noticias guiadas por medio de RA.

Uno de los propósitos planteados en el estudio era determinar si además de la RA también se empleaban otros recursos existentes en el plató, como las pantallas, para favorecer una mayor inmersión del espectador. Como se ha podido comprobar, esta circunstancia no es todavía demasiado habitual. Tan sólo un 32\% las utilizan, y de entre las tres ediciones es en Noticias 1 donde se vinculan más frecuentemente los contenidos y la pantalla de plató. De hecho, en el telediario de mediodía la mitad de las noticias (51\%) se valen de este recurso. De otro lado, al igual que los contenidos envolventes resultan anecdóticos, también lo es la sensación de inmersión del/la presentador/a dentro de los recursos de RA. Esta circunstancia ocurre tan sólo en un $4 \%$ de los ítems analizados y resulta similar en todas las ediciones, siendo la del fin de semana la única que no padece esta situación.

Ilustración 4. Interacción entre la RA y la pantalla del plató en Antena 3 Noticias

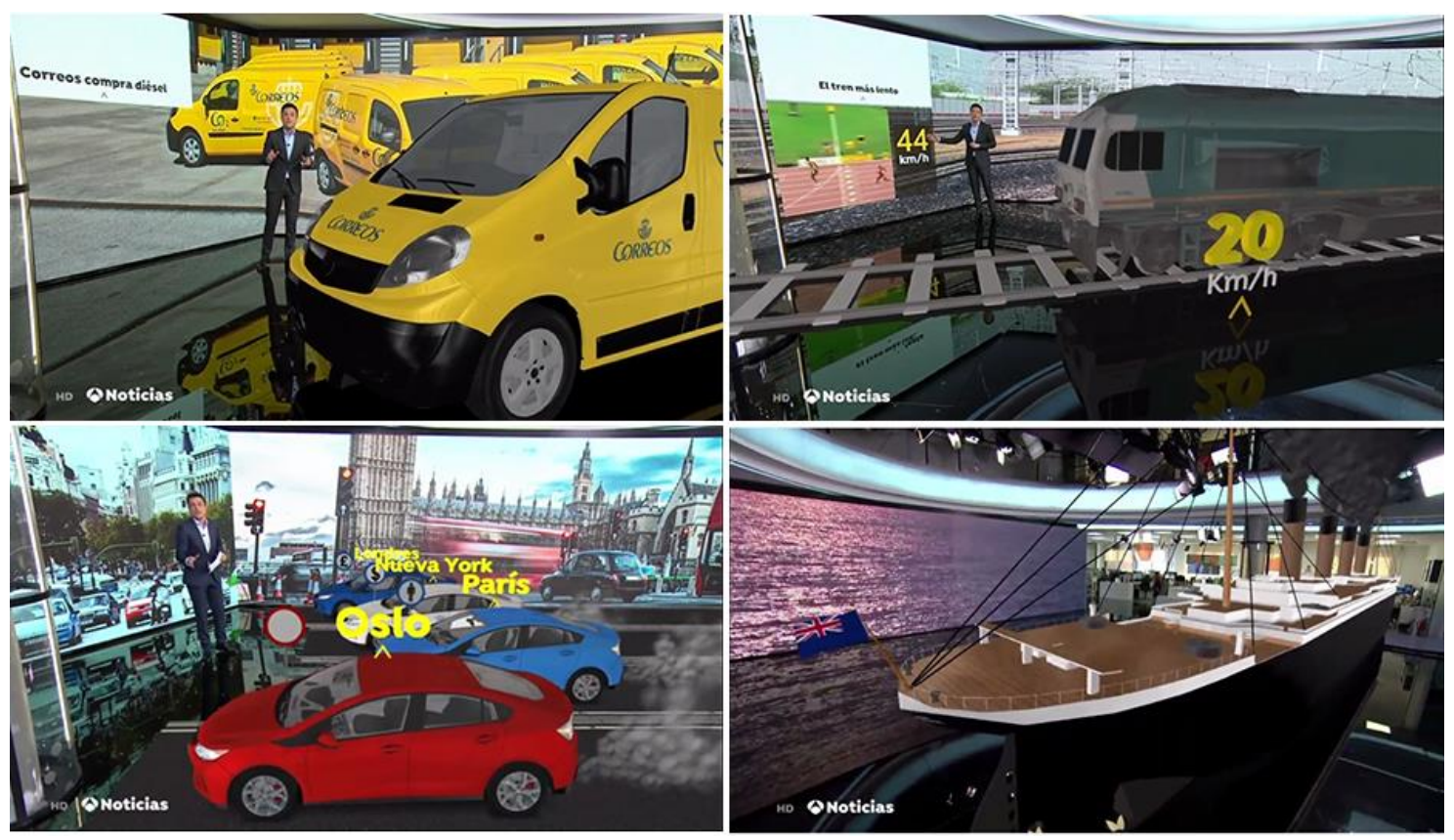

Fuente: Antena 3

Otra de las características a analizar sobre la figura del/la presentador/a era conocer el grado de interacción con respecto al contenido en RA. Para ello, se escogieron las siguientes categorías: limitada -únicamente menciona el contenido-, elevada -lo utiliza activamente para la explicación e interpretación de las noticias-, e interacción nula. En algo más de la mitad de las noticias con RA no ocurre una interacción por parte del/la presentador/a (52\%), ya que se trata mayoritariamente de elementos Figuras de titulación. Sí ocurre, sin embargo, en el 48\% restante, traduciéndose en que interactúan de forma activa en el 30\% de las informaciones y con una cierta limitación en el $18 \%$ de casos.

Como vemos con anterioridad, es, especialmente, en las noticias del mediodía donde se detecta una relación más estrecha entre presentador/a y contenidos en RA, seguido de Noticias 2. En Noticias 1 la mayor parte de estos elementos tienen una interacción elevada (43\%) o limitada (36\%). En Noticias 2 y Noticias Fin de Semana predominan aquellos en los que no existe interacción con el/la presentador/a, y se sitúan en torno a un $70 \%$ en los dos telediarios. 
Figura 5. Interacción entre presentador/a y contenidos en RA (distribución por ediciones)

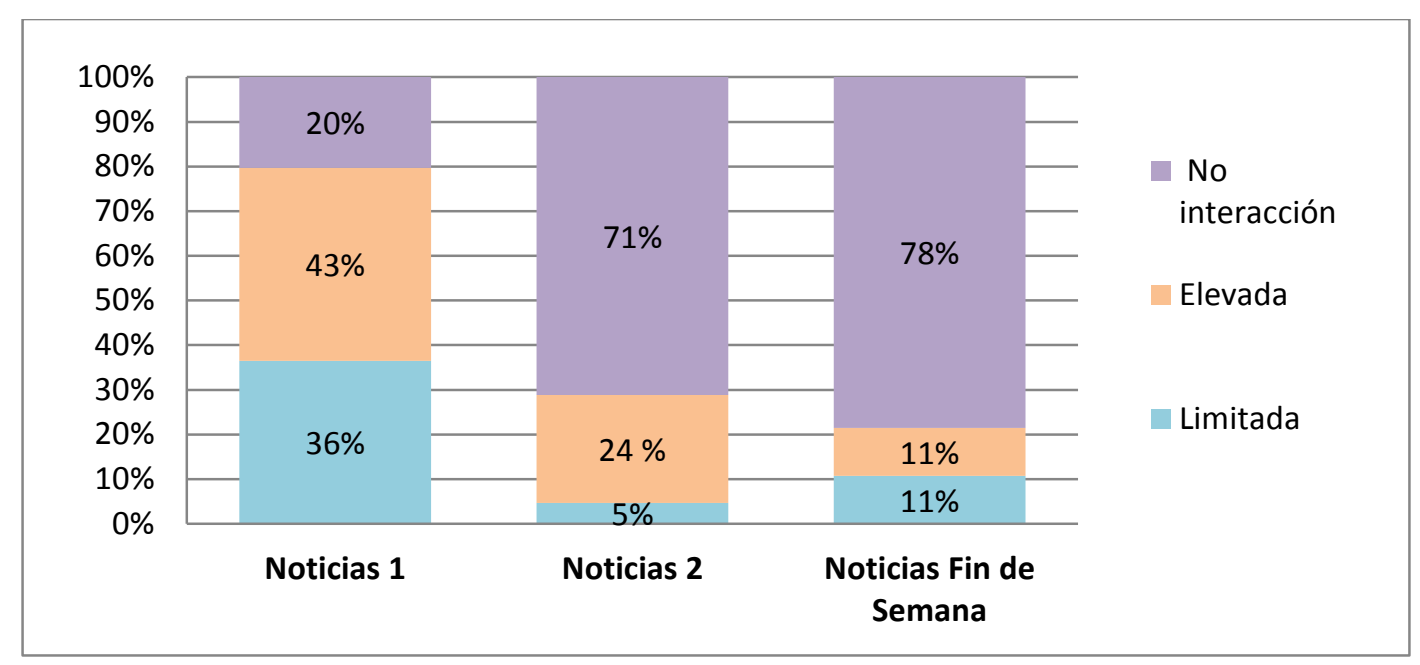

Fuente: Elaboración propia.

De igual manera, es menor el porcentaje de noticias en las que la RA se utiliza para introducir datos que acompañen a la narración. Tan sólo un 35\% de estas informaciones los incluyen, exponiendo los acontecimientos de una manera más gráfica. Por ediciones, es en Noticias 1 donde se hace un uso más intensivo, concretamente en un $47 \%$ de las noticias, frente al $28 \%$ de Noticias 2 y el 25\% de Noticias Fin de Semana.

Otra de las categorías de análisis se refiere al objetivo principal que cumplen los contenidos dentro de la noticia; esto es, si se utilizan como un recurso informativo que mejore la comprensión de los acontecimientos o si, por el contrario, su cometido es el de atraer el interés de la audiencia a través de este tipo de elementos que hacen más atractiva la narración de los hechos. Los resultados muestran que los contenidos analizados poseen un objetivo principalmente informativo (84\%), en comparación a un escaso $16 \%$ que destaca por su finalidad estética.

El estudio pormenorizado de las tres ediciones evidencia dos tendencias en cuanto al propósito principal que cumplen estos elementos virtuales. Por un lado, los resultados de Noticias 1 reflejan una proporción más pareja entre ambas categorías, aunque prevalecen los contenidos informativos (68\%) frente a los estéticos (32\%). Sin embargo, tanto en Noticias 2 como en la edición de fin de semana la diferencia entre las opciones se acentúa en gran medida, decantándose también por los contenidos informativos con porcentajes muy similares (94\% y $96 \%$, respectivamente).

Estrechando el foco en torno a las funciones específicas que cumplen los contenidos, prevalece la de ejercer como elemento de transición que divide las noticias o los bloques de contenido en los telediarios. Y es que casi la mitad de ítems (44\%) son rótulos que presentan las informaciones. Le siguen a cierta distancia la opción de ampliar los datos de la noticia, cuyo porcentaje se sitúa en torno al $22 \%$, así como la función de ejercer como un elemento estético $(15 \%)$ y la de ubicar al espectador en el contexto espaciotemporal de la noticia (4\%). 
Ilustración 5. La ampliación de datos por medio de mapas o figuras es una de las funciones principales de la RA en Antena 3 Noticias
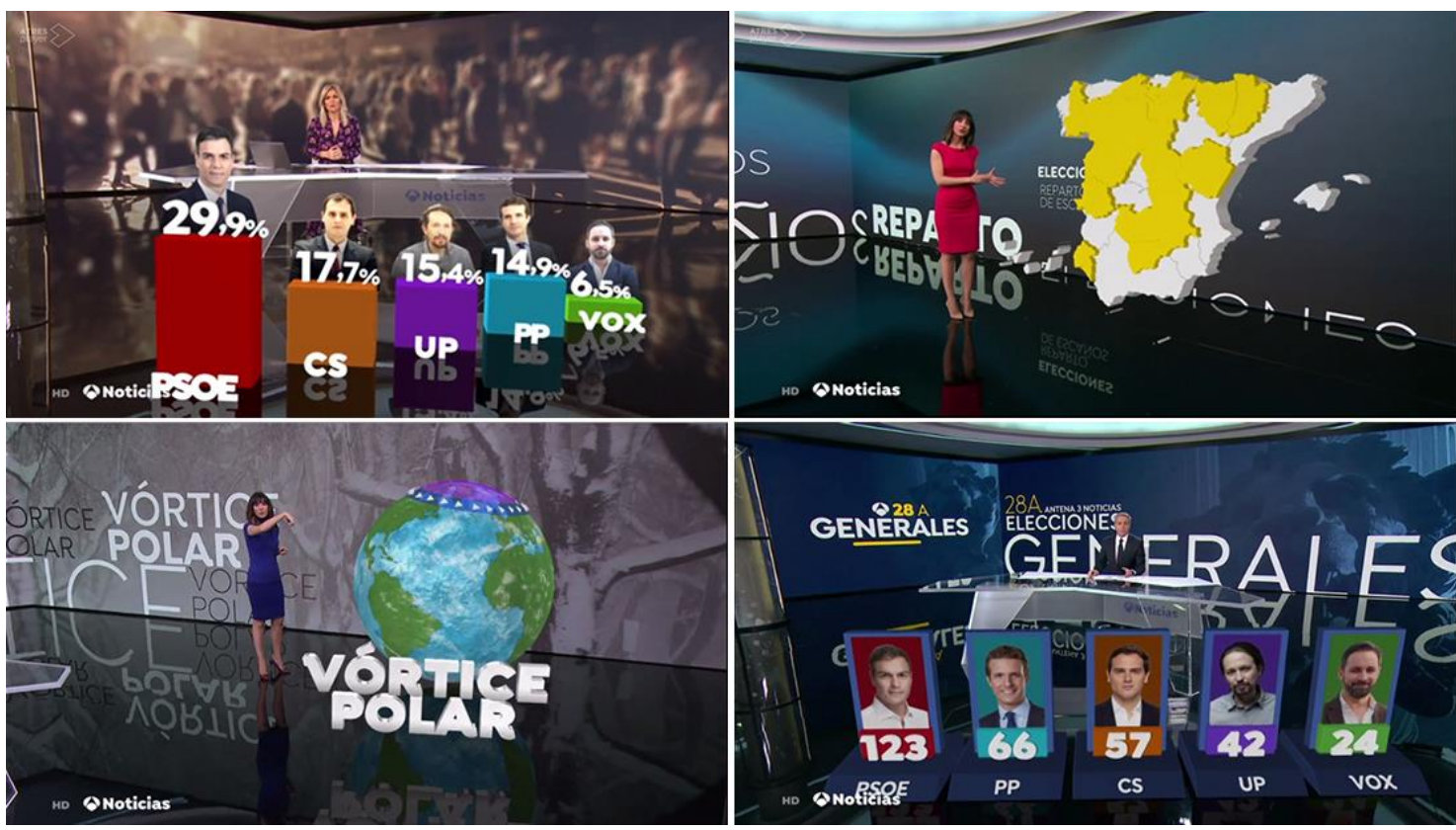

Fuente: Elaboración propia.

En este punto cabe subrayar que, de acuerdo con los resultados obtenidos tras la realización de un testeo previo, se decidió incorporar la función que aúna la ampliación de datos y la ubicación del espectador, debido al gran número de ítems en los que se daban ambos propósitos. Estos suponen el $15 \%$ del total. No obstante, la suma de las categorías anteriormente mencionadas ampliar datos, ubicar al espectador y el apartado que aúna a ambas- se eleva hasta el $41 \%$ y se sitúa muy próxima a la función de transición entre informaciones.

Figura 6. Funciones de los contenidos de Realidad Aumentada (distribución por ediciones)

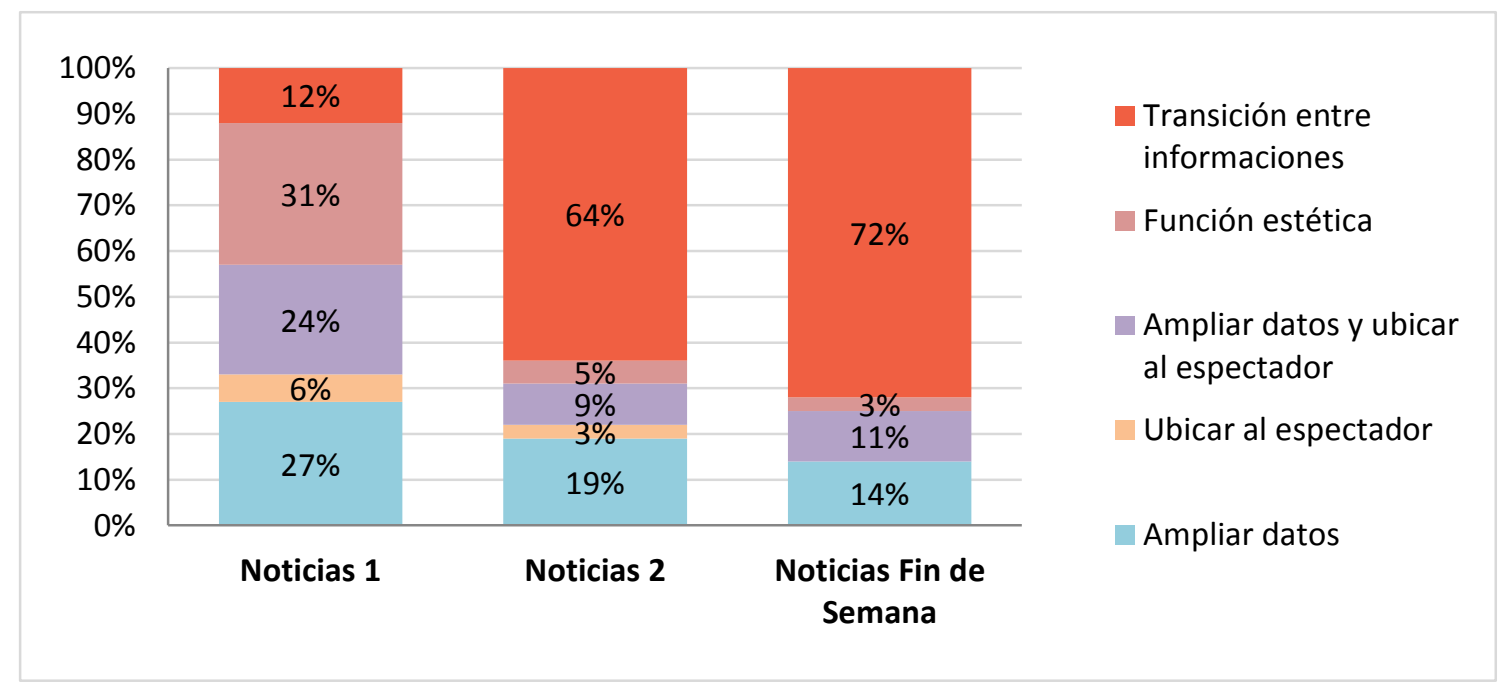

Fuente: Elaboración propia.

Los resultados por ediciones informativas muestran una cierta variedad en la distribución de los porcentajes correspondientes a Noticias 1 . La función estética se sitúa a la cabeza (31\%), a la que siguen de cerca la ampliación de datos $(27 \%)$ y la función que la vincula con la ubicación del espectador (24\%). Si sumamos las tres categorías mencionadas en el párrafo previo, la 
ampliación de datos y la ubicación del espectador son la función principal de los contenidos, con el $57 \%$ del total.

Una vez más, los resultados de la edición nocturna y la de fin de semana muestran notables semejanzas. En ambas sobresale la transición entre informaciones (64\% en Noticias 2 y $72 \%$ en Noticias Fin de Semana), a mucha distancia de la ampliación de datos (19\% en Noticias 2 y $14 \%$ en Noticias Fin de Semana). En ambos casos, el resto de las categorías apenas tienen incidencia. Asimismo, y al contrario de lo que ocurría en la edición de mediodía, la suma de las tres categorías referentes a ampliación de datos y ubicación del espectador se eleva al $31 \%$ y al $24 \%$, respectivamente, pero quedan bastante alejados de la categoría principal.

Figura 7. Forma de los contenidos de Realidad Aumentada creados por Antena 3 Noticias

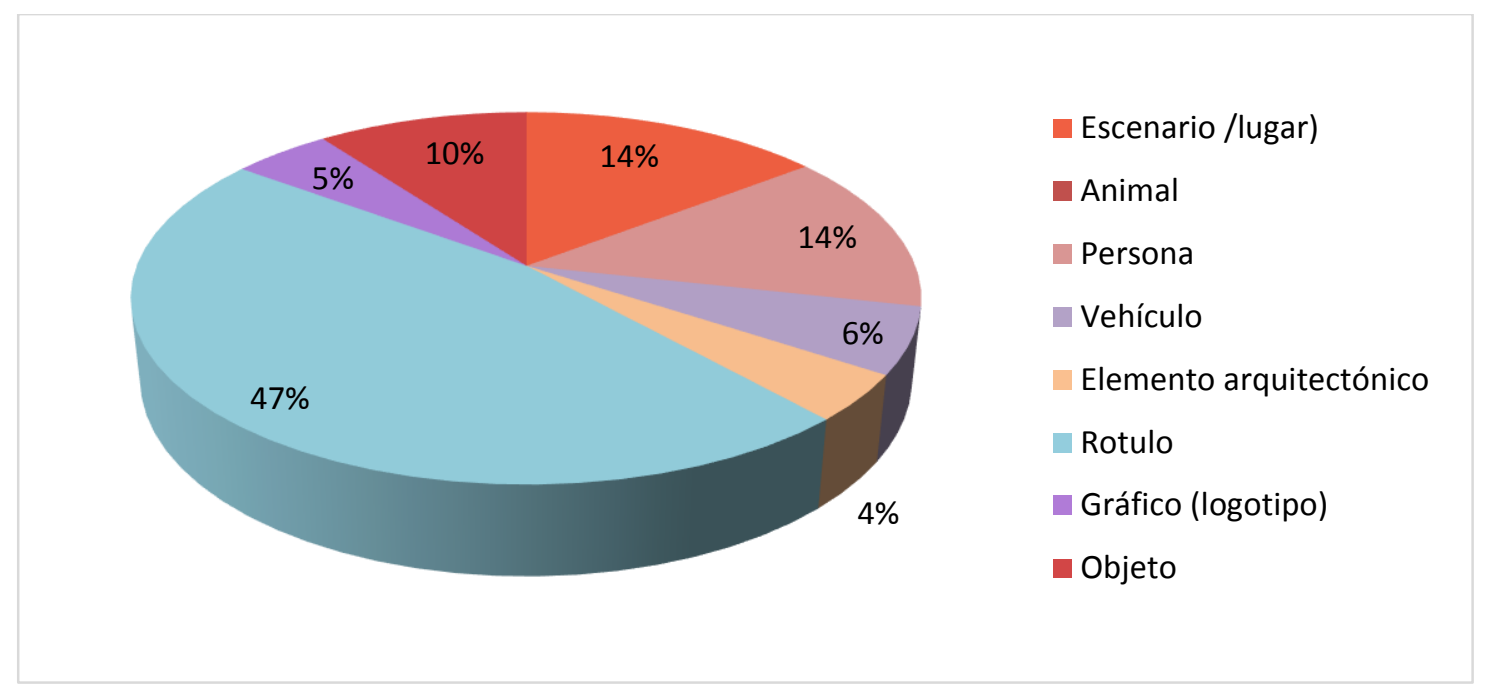

Fuente: Elaboración propia.

En la línea de los resultados obtenidos en la categoría de funciones, cerca de la mitad (47\%) de los contenidos del corpus son rótulos de texto. La otra mitad se divide de forma similar entre el resto de las categorías. Entre ellas destacan los escenarios o lugares (14\%), las personas (14\%) y los objetos (10\%), las tres categorías más comunes.

Si comparamos los porcentajes de las tres ediciones informativas, podemos afirmar que en Noticias 1 todas las categorías acumulan porcentajes similares, mientras que en Noticias 2 y Noticias Fin De Semana abundan los contenidos con forma de rótulo. El estudio pormenorizado de Noticias 1 indica que los contenidos con figuras de personas son la categoría principal (27\%), seguidas de los escenarios o lugares (20\%), rótulos (15\%), objetos (13\%) y vehículos $(12 \%)$. Los porcentajes de elementos arquitectónicos y logotipo se sitúan en torno al 6\%.

Noticias 2 muestra una clara predilección por los rótulos, utilizándose en casi 7 de cada 10 informaciones. El resto de las categorías son residuales, destacando los escenarios (11\%) y objetos (9\%), siguiendo la tendencia general. Finalmente, los sábados y domingos también se usan sobre todo los rótulos, siendo éstos aún más abundantes (71\%) que en el telediario nocturno. Entre los porcentajes restantes únicamente encontramos tres categorías: el $14 \%$ de contenidos donde las personas son protagonistas, el $11 \%$ de escenarios y el $4 \%$ de objetos. 
Ilustración 6. La RA permite a la audiencia ubicarse en el escenario de la noticia

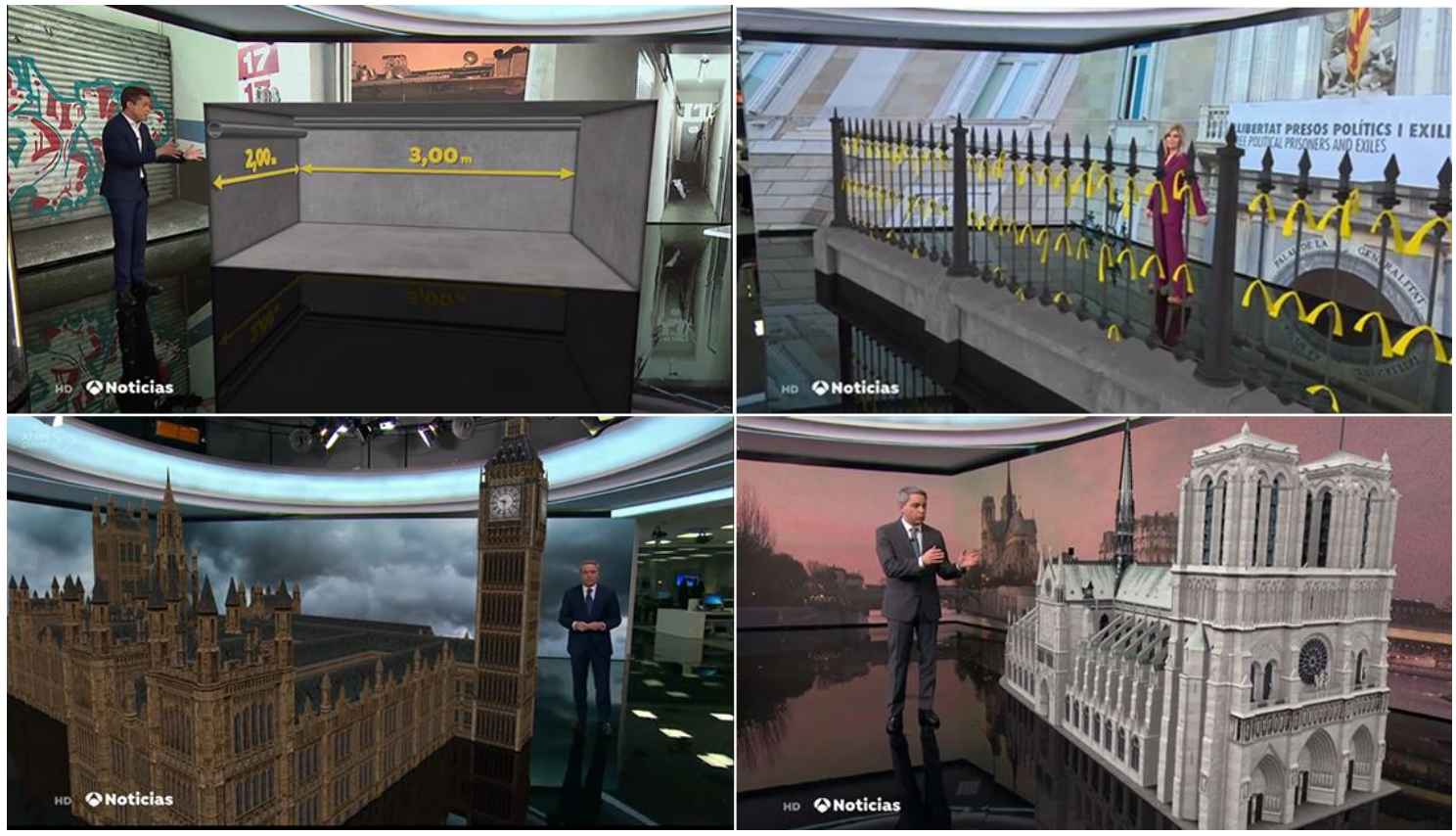

Fuente: Elaboración propia.

El último de los componentes analizados son los elementos adicionales que suceden a la RA en las noticias, ya que siempre van acompañadas de otros recursos audiovisuales que las complementan. En este caso, los vídeos son los elementos que más se han detectado tras la aparición de los contenidos en la pantalla, en más de la mitad de las ocasiones (54\%). La segunda opción son las intervenciones del/la presentador/a en plató (24\%), seguidas de las conexiones en directo en el lugar de los hechos (17\%) y la aparición de Figuras o tablas explicativas en las pantallas $(5 \%)$.

Figura 8. Elementos que acompañan a los contenidos de RA (distribución por ediciones)

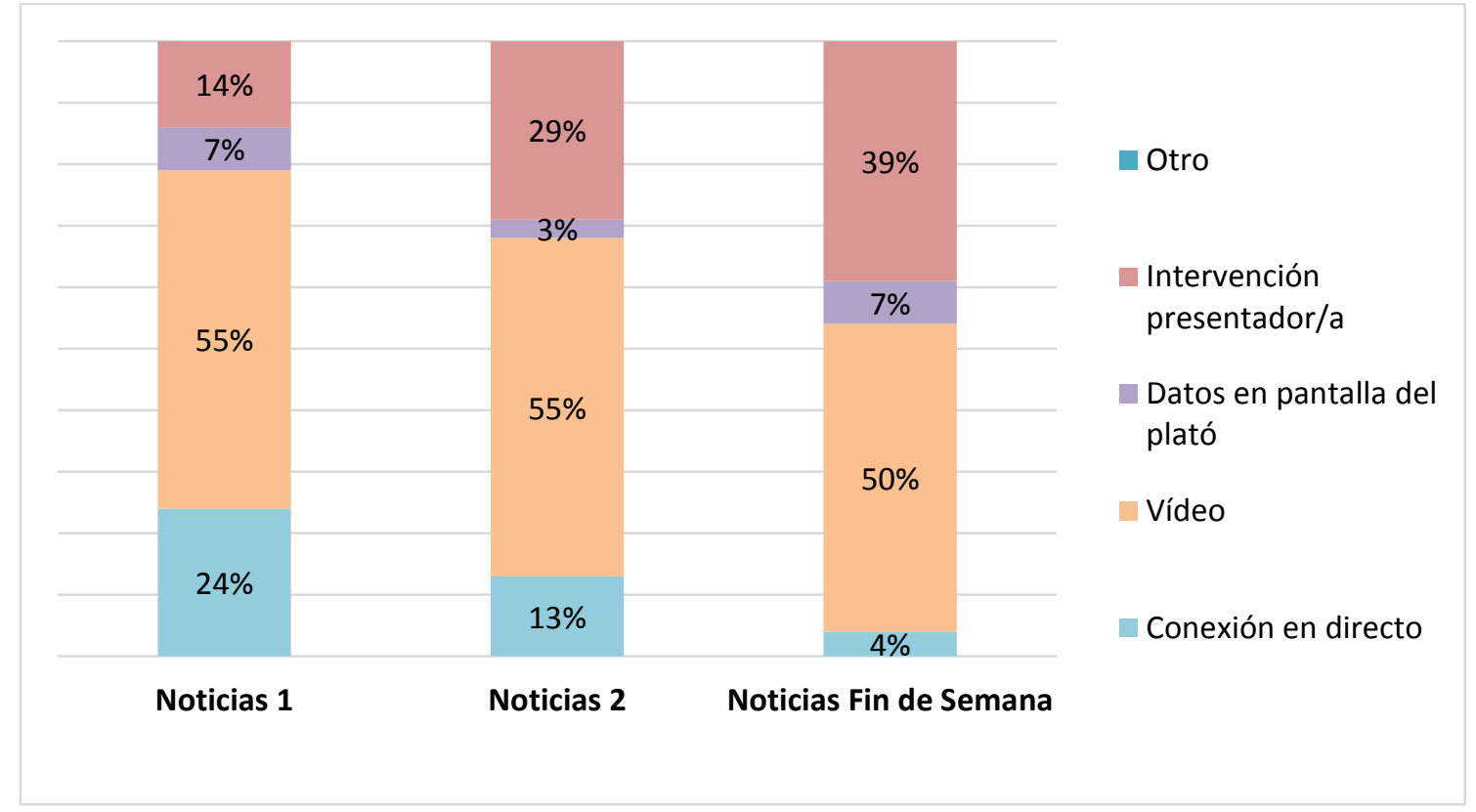

Fuente: Elaboración propia. 
En concordancia con la tendencia general, el vídeo es la opción principal en todas las ediciones (55\% en Noticias 1 y Noticias 2, y 50\% en Fin de Semana) y obtiene porcentajes muy similares. La distribución de las otras categorías, por el contrario, se encuentra condicionada a la edición de la que se trata. Esto es, en la edición del mediodía abundan más las conexiones en directo (24\%) que las intervenciones de los/las presentadores/as (14\%) o los datos en pantalla (7\%) tras la aparición de un contenido.

El informativo de la noche sitúa a la participación del/la presentador/a en segundo lugar, con casi un tercio de las informaciones (29\%), seguida de las conexiones en directo (13\%) y los datos en pantalla (3\%). Por último, en el formato de fin de semana son las intervenciones de los presentadores (39\%) y la aparición de datos en la pantalla del plató $(7 \%)$ las que más suceden a los contenidos, en detrimento de las conexiones en directo (4\%).

\section{Conclusiones}

En términos generales, es posible afirmar que la RA se va implantando de forma progresiva en Antena 3 Noticias, si bien es cierto que es una tecnología en continua evolución con un largo camino todavía por recorrer. Los resultados obtenidos diferencian tres grandes tipologías de contenidos en RA. En primer lugar, los rótulos de texto, estáticos y sin apenas interacción, utilizados a modo de transición entre noticias y bloques informativos, y como presentación del tema. Por otro, algunos productos cuya principal función, con un mayor o menor nivel de complejidad e interactividad, se limitan a presentar la noticia de una manera más atractiva. Sin embargo, lo que los autores denominan función estética nunca deja de ser, en parte, también informativa, ya que muestra los escenarios o protagonistas de la noticia de una manera gráfica.

En último término está la RA de gran complejidad y elaboración, menos abundante por el momento, aunque constituye una útil herramienta para la interpretación de datos y la mejora de la comprensión de acontecimientos. Entre ellos destacan los contenidos envolventes o inmersivos, todavía anecdóticos en los telediarios, aunque cada vez más habituales. Esta circunstancia resulta totalmente comprensible debido a la gran cantidad de recursos técnicos y humanos necesarios para su elaboración. Por tanto, no es de extrañar que se encuentren frecuentemente en noticias que forman parte de la agenda de previsiones informativas diarias o en temas que se prolongan en el tiempo como el Brexit, las elecciones generales en España o la crisis de los aviones Boeing 737. Igualmente, el estudio sugiere un mayor aprovechamiento de la infraestructura envolvente con la que cuenta la escenografía virtual del plató, un aspecto no demasiado explotado en esta etapa inicial.

Algo similar ocurre con las dos tipologías de RA restantes (estáticas y móviles), que también aparecen más en acontecimientos previsibles. Se han detectado, no obstante, algunos casos en los que al tratarse de un acontecimiento de alto interés informativo se han realizado contenidos muy elaborados a pesar de tratarse de hechos fortuitos. Hablamos, por ejemplo, del rescate de Julen, el niño que se cayó a un pozo en la localidad de Totalán (Málaga), o del incendio que afectó a la catedral de Notre Dame (París).

Otro de las principales conclusiones extraídas es la clara prevalencia de la función informativa de la RA frente a un propósito estético, en concordancia con el "contar más y mejor" que defiende el director de Antena 3 Noticias, Santiago González. La quinta hipótesis planteada en el estudio queda, por tanto, descartada. Al hilo de esta cuestión, los datos muestran que las noticias con RA se sitúan al inicio del telediario, y tanto el propio producto como el tiempo dedicado al tema que trata tienen una duración prolongada. La conjugación de estos aspectos arroja una interesante lectura, al estimar que se trata mayoritariamente de contenidos informativos a los que se confiere un alto valor. 
El análisis de las temáticas más recurrentes en el empleo de dicha tecnología lo lidera la sección de Sociedad, así como Política e Internacional. Retomando los valores/noticia de Wolf (1987) planteados en el marco referencial, dichas secciones concuerdan con algunos de los factores expuestos por el autor como la identificación del espectador con los acontecimientos, el impacto sobre la nación y el interés nacional, la cantidad de personas implicadas, etc. En otras palabras, la RA figura frecuentemente como un complemento informativo en las noticias de mayor interés para el gran público.

A pesar de este nexo común, la edición del telediario en la que se ubique esta tecnología condiciona en gran medida su utilización. Tanto es así que Noticias 1 muestra un comportamiento diferenciado con respecto a Noticias 2 y a Noticias Fin de Semana. Esto se traduce en una mayor heterogeneidad en la forma y funciones de la RA o en la creación de contenidos más inmersivos e integrados con los elementos de la escenografía virtual. Esto quizá pueda deberse a que, como se explicitaba en la introducción, la edición de mediodía posee la mayor audiencia de consumo de informativos en España, lo que podría explicar una mayor complejidad de todos los aspectos analizados.

La edición de la noche cuenta con un mayor número de contenidos en RA que el resto, previsiblemente siguiendo la lógica que dictamina que el equipo de grafismo, responsable de estos elementos, dispone de más tiempo para su elaboración. En ella prevalecen los rótulos de texto, al igual que en Noticias de Fin de Semana, con quien comparte otros patrones comunes. En el caso de esta última se aprecia una notable disminución de la RA, siendo estos elementos los menos elaborados en cuanto a la inmersión, interacción con la pantalla, etcétera. Podría decirse, por tanto, que esta tecnología se utiliza principalmente en las dos ediciones diarias.

Con todo, a las funciones de ampliación de datos y de ubicación del espectador les es conferido cada vez un mayor peso, destacando el propósito explicativo de la RA y dotando de valor a la necesaria figura del/la presentador/a, quien actúa como guía en la interpretación de los contenidos y acompaña a la audiencia a lo largo de la narración.

\section{Discusión}

Esta que presentamos se perfila como una de las primeras investigaciones focalizadas en analizar en profundidad la RA en el ámbito mediático, y más concretamente en televisión. Lo innovador del objeto de estudio coincide, en este sentido, con el ya mencionado papel precursor de Antena 3 en el uso diario de esta tecnología. Otra de las aportaciones del paper es tratar de ofrecer una primera aproximación terminológica dentro del campo de estudio de la RA en televisión, estableciendo una categorización propia de los distintos aspectos estudiados. La falta de estudios previos similares ha supuesto, en este punto, una cierta limitación para los autores. Igualmente, se ha visto la necesidad de crear una ficha de análisis que podría resultar útil para futuras investigaciones, pudiendo ser actualizada de acuerdo a los objetivos marcados. Junto a lo mencionado, la investigación busca establecer una vinculación entre lo clásico y lo actual, esto es, entre los valores de selección de noticias propuestos por Mauro Wolf a comienzos de los 90 y las nuevas narrativas periodísticas.

Cierto es, sin embargo, que este proyecto cuenta con un margen de mejora en diversos aspectos entre los que se encuentra la ampliación del objeto de estudio. Se ha tratado de realizar un notable esfuerzo en la creación del corpus, abarcando los principales telediarios de la cadena. Sin embargo, sería interesante poder incluir las restantes, así como la sección de deportes. También sería deseable sumar el estudio del programa de debate de actualidad política Al Rojo Vivo, emitido en otra de las cadenas del grupo Atresmedia, al que pertenece Antena 3. Y es que, junto a los informativos analizados, es otro de los máximos exponentes en el uso de la RA. 
Además de la ampliación de la muestra, un periodo de estudio más extenso permitiría ahondar en la evolución temporal de la RA. Este extremo, no obstante, resulta harto complicado debido a la disponibilidad temporal del material. A pesar de contar con la hemeroteca digital Atresplayer, los telediarios de Antena 3 no se encuentran online de forma permanente. Esta circunstancia ha condicionado la elección de la fecha de inicio, imposibilitando dar comienzo al estudio en el mismo momento de su implantación.

La Realidad Aumentada, actualmente en auge, cuenta con un amplio recorrido académico previo, principalmente vinculado a otros ámbitos ajenos a los medios. Por ello, se percibe como un campo de estudio con un elevado potencial de futuro. Esta investigación, por ejemplo, pudiera ser replicable a otras cadenas de ámbito autonómico, estatal e internacional, así como servir de guía para estudiar el seguimiento de casos informativos concretos. Otros aspectos sumamente interesantes para su análisis son la configuración de las nuevas rutinas de trabajo, así como las actitudes, percepciones y comportamientos de las audiencias con respecto a estos nuevos elementos virtuales.

\section{Bibliografía}

Abril, D. (2012). Realidad Aumentada. Madrid: Universidad Carlos III. Recuperado de https://bit.ly/2Enov4B

Antena 3 (30 de agosto de 2018). Santiago González, director de Antena 3 Noticias, apuesta por la innovación tecnológica como complemento de un proyecto informativo consolidado. Antena 3. Recuperado de https://bit.ly/2Ec4Y7U

Ashford, R. (2010). QR codes and academic libraries. Reaching mobile users. C\&RL News, 71(10), pp. 526-530. Recuperado de https://bit.ly/2JIFSzk

Ashton, K. (22 de junio de 2009). That Internet of Things Thing. RFID Journal. Recuperado de https://bit.ly/2JCPfBW

Asociación para la Investigación de Medios de Comunicación (2018). Resumen general de resultados Estudio General de Medios (EGM) $3^{a}$ Ola de 2018. Madrid: AIMC. Recuperado de https://bit.ly/2Edrz4y

Azuma, R. T. (1997). A survey of augmented reality. Presence: Teleoperators \& Virtual Environments, 6(4), pp. 355-385. Recuperado de https://bit.ly/2GPugM2

Barabas, J. (2014). Holographic television: measuring visual performance with holographic and other 3D television technologies. Massachusetts: Massachusetts Institute of Technology. Recuperado de https://bit.ly/2JMnu8Q

Barlovento Comunicación (2018). Análisis televisivo 2018. Madrid: Barlovento Comunicación. Recuperado de https://bit.ly/2GKCaae

Barlovento Comunicación (2019). Análisis del Comportamiento de la Audiencia TV en Abril de 2019. Madrid: Barlovento Comunicación. Recuperado de https://bit.ly/2E90Nd1

Barroso, J., y Pérez, Ó. M. G. (2016). La realidad aumentada y su aplicación en la educación superior. Revista Caribeña de Investigación Educativa (RECIE), 1(2), pp. 111-124. doi: https://doi.org/10.32541/salome.2016.v1i2.pp111-124

Bove, V. M. (2010). What is holographic television, and will it ever be in my living room?.International Conference on Stereoscopic 3D for Media and Entertainment, 1-10. New 
York: Society of Motion Picture and Television Engineer (SMPTE). Recuperado de https://bit.ly/2XCVdaW

Brainstorm Multimedia (2013). Antena 3 TV: Virtual Reality Elections. Brainstorm Multimedia, pp. 1-2. Recuperado de https://bit.ly/2JjZMmp

Brainstorm Multimedia (2018). TVE: TeleTransporter for Elections. Brainstorm Multimedia, pp. 1-2. Recuperado de https://bit.ly/2HkpS6E

Burdea, G., y Coiffet, P. (1996). Tecnologías de la realidad virtual. Barcelona, España: Paidós.

Caldera-Serrano, J. (2014). Realidad aumentada en televisión y propuesta de aplicación en los sistemas de gestión documental. El profesional de la información, 23(6), pp. 643-650. doi: https://doi.org/10.3145/epi.2014.nov.12

Canavilhas, J. (2013). El periodismo en los tiempos de un nuevo ecosistema mediático: propuestas para la enseñanza superior. Historia y Comunicación Social, 18, pp. 511-521. doi: https://doi.org/10.5209/rev_HICS.2013.v18.44259

Caudell, T.P. \& Mizell, D.W. (1992). Augmented reality: An application of heads-up display technology to manual manufacturing processes. Hawaii International Conference on System Sciences, (2), pp. 659-669. Hawaii: University of Hawaii. doi: https://doi.org/10.1109/HICSS.1992.183317

De la Torre-Cantero, J., Martín-Dorta, N., Pérez, J. L. S., Carrera, C. C., y González, M. C. (2013). Entorno de aprendizaje ubicuo con realidad aumentada y tabletas para estimular la comprensión del espacio tridimensional. Revista de Educación a Distancia, (37), pp. 1-17. Recuperado de https://bit.ly/2UhFYSw

Drascic, D. y Milgram, P. (1996). Perceptual issues in augmented reality. Stereoscopic Displays and Virtual Reality Systems III, (2653), pp. 123-134. San José (EEUU): International Society for Optics and Photonics. doi: https://doi.org/10.1117/12.237425

Fermín-Lobo, M. (2013). Integrando realidad aumentada basada en móvil en entornos elearning. Oviedo: Universidad de Oviedo. Recuperado de https://bit.ly/2T5tRLH

Fidler, R. (1998). Mediamorfosis: comprender los nuevos medios. Buenos Aires: Ediciones Granica.

Fombona, J., Pascual, M. A. y Madeira, M. F. (2012). Realidad aumentada, una evolución de las aplicaciones de los dispositivos móviles. Píxel-Bit. Revista de Medios y Educación, (41), pp. 197-210. Recuperado de https://bit.ly/2eD1PkP

Fundación Telefónica. (2011). Realidad Aumentada. Una nueva lente para ver el mundo. Madrid/Barcelona: Fundación Telefónica/Ariel. Recuperado de https://bit.ly/32vGBMP

Galán-Cubillo, E. (2008). Escenografía virtual en TV. Análisis del uso de escenografía virtual en la realización de un programa de televisión. Revista latina de comunicación social, (63), pp. 31-42. doi: https://doi.org/10.4185/RLCS-63-2008-752-031-042

Galán-Cubillo, E. (2010). La realidad virtual en televisión: el paso del átomo al bit. Ámbitos (19), pp. 9-24. Recuperado de https://bit.ly/2Nz0mfv

Grewal, M.S., Andrews, A.P. \& Bartone, C.G. (2013). Global Navigation Satellite Systems, Inertial Navigation and Integration. New Jersey: John Willey \& Sons. Recuperado de https://bit.ly/2xPaTfz 
Herrero de la Fuente, M. (2017). Nuevas fórmulas para la televisión en directo: el uso de Facebook Live en Atresmedia. Miguel Hernández Communication Journal (8), pp. 521-563. doi: https://doi.org/10.21134/mhcj.v0i8.202

Hill, R. (14 de junio de 2011). What Augmented Reality Can Do for the Media Industry. MediaShift. Recuperado de https://bit.ly/2YYmuVw

Höllerer, T. H. \& Feiner, S. K. (2004). Mobile Augmented Reality. En Karimi, H. \& Hammad, A. (Eds.), Telegeoinformatics: Location-Based Computing and Services (pp. 1-39). Florida: CRC Press. Recuperado de https://bit.ly/2wb3g4U

Ilic, A. \& Flesich, E. (2016). Augmented Reality and the Internet of Things. Auto-ID Labs White Paper. Zurich: Auto-ID Labs.

doi: https://doi.org/10.13140/RG.2.2.22003.12321

Infante, Á. C., Jácome, D. R., y Chicaiza, R. P. M. (2016). Reconocimiento de fachadas mediante realidad aumentada como medio publicitario. 3c Tecnología, 5(2), pp. 54-64. doi: https://doi.org/10.17993/3ctecno.2016.v5n2e18.54-64

Kerawalla, L., Luckin, R., Seljeflot, S., y Woolard, A. (2006). "Making it real": exploring the potential of augmented reality for teaching primary school science. Virtual reality, 10(3-4), pp. 163-174. doi: https://doi.org/10.1007/s10055-006-0036-4

KPMG (2019). Presente y futuro del sector media. Claves y perspectivas de un sector en transformación. KMPG España. Recuperado de https://bit.ly/30wjJuX

Leonhardt, D., Rudoren, J., Galinsky, J., Skog, K., Lacey, M., Giratikanon, T. \& Evans, T. (Enero de 2017). Journalism That Stands Apart. The New York Times. Recuperado de https://nyti.ms/2JRfgex

Martín, M. J. A. (2015). Aplicaciones de la realidad aumentada en el ámbito de la enseñanza superior. Diseño de un proyecto piloto. Cuadernos de Gestión de Información, 5(1), pp. 18-35. Recuperado de https://bit.ly/2Ggod1b

Meneses- Fernández, M. D., y Martín-Gutiérrez, J. (2016). Medios de comunicación impresos y realidad aumentada, una asociación con futuro. Arbor, 192(777), p. 292-304. doi: https://doi.org/10.3989/arbor.2016.777n1008

Meneses-Fernández, M. D., y Martín-Gutiérrez, J. (2013). Realidad aumentada e innovación tecnológica en prensa. La experiencia de ver y escuchar un periódico impreso. Estudios sobre el mensaje periodístico, 19(1), pp. 207-222.

doi: https://doi.org/10.5209/rev_ESMP.2013.V19.N1.42517

Milgram, P., \& Kishino, F. (1994). Taxonomy of mixed reality visual displays. IEICE Transactions on Information Systems, 77(12), pp. 1321-1329. Recuperado de https://bit.ly/2HezCQa

Otegui-Castillo, J. (2017). La realidad virtual y la realidad aumentada en el proceso de marketing. Bilbao: Universidad del País Vasco. Recuperado de https://bit.ly/2YcflDC

Parhizkar, B., Al-Modwahi, A. A. M., Lashkari, A. H., Bartaripou, M. M. I., \& Babae, H. R. (2011). A survey on web-based AR applications. International journal of computer science issue, 8(4), 471-479. Recuperado de https://bit.ly/2TvXmGa

Parra, D., Edo, C., y Marcos, J. C. (2017). Análisis de la aplicación de las tecnologías de realidad aumentada en los procesos productivos de los medios de comunicación españoles. Revista Latina de Comunicación Social, 72, pp. 1670-1688. doi: https://doi.org/10.4185/RLCS-2017-1240 
Pavlik, J. V. (2001). Journalism and new media. New York: Columbia University Press.

Pavlik, J. V., \& Bridges, F. (2013). The emergence of Augmented Reality (AR) as a storytelling medium in journalism. Journalism \& Communication Monographs, 15(1), pp. 4-59. doi: https://doi.org/10.1177/1522637912470819

Ruiz-Davis, S., y Polo-Serrano, D. (2012). La realidad aumentada como nuevo concepto de la publicidad online a través de los smartphones. Razón y palabra, 17(80), pp. 293-307. Recuperado de https://bit.ly/32rfToJ

Sánchez-García, E. M. (2019). Integración dinámica de objetos sintéticos en escenas reales. Valencia: Universidad Politécnica de València. Recuperado de https://bit.ly/2xTfnSk

Scolari, C. A. (2013). Narrativas transmedia: Cuando todos los medios cuentan. Barcelona: Deusto S.A. Ediciones.

Sirkkunen, E., Väätäjä, H., Uskali, T., \& Rezaei, P. P. (2016). Journalism in virtual reality: opportunities and future research challenges. Proceedings of the 20th International Academic Mindtrek Conference, 297-303. New York: ACM.

doi: https://doi.org/10.1145/2994310.2994353

Spector, J. M., Merrill, M. D., Elen, J., \& Bishop, M. J. (2014). Handbook of research on educational communications and technology. New York: Springer. doi: https://doi.org/10.1007/s10758-014-9231-7

Thornton, T. (10 de noviembre de 2010). Augmented Reality Invades Newsrooms, Kids's Shows, Ads. MediaShift. Recuperado de https://bit.ly/2Sj6ECa

Väätäjä, H. K., Ahvenainen, M. J., Jaakola, M. S., \& Olsson, T. D. (2013). Exploring augmented reality for user-generated hyperlocal news content. CHI'13 Extended Abstracts on Human Factors in Computing Systems, 967-972. Nueva York: ACM. doi: https://doi.org/10.1145/2468356.2468529

Vargas-Alzate, D. (2012). La realidad aumentada en la producción de mensajes periodísticos visuales. Colombia: Universidad Autónoma de Occidente. Recuperado de https://bit.ly/2LpbMUU

Vate-U-Lan, P. (2012). An augmented reality 3D pop-up book: the development of a multimedia project for English language teaching. 2012 IEEE International Conference on Multimedia and Expo, 890-895. Melbourne (Australia): Institute of Electrical and Electronics Engineers. doi: https://doi.org/10.1109/ICME.2012.79

Wolf, M. (1987). La investigación de la comunicación de masas. Barcelona: Paidós.

Yilmaz, R. M., \& Goktas, Y. (2017). Using augmented reality technology in storytelling activities: examining elementary students' narrative skill and creativity. Virtual Reality, 21(2), pp. 75-89. doi: https://doi.org/10.1007/s10055-016-0300-1 